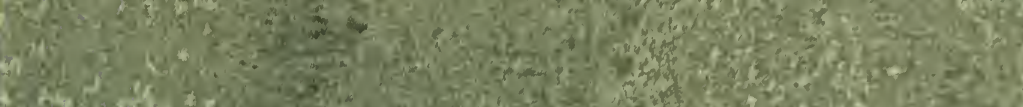

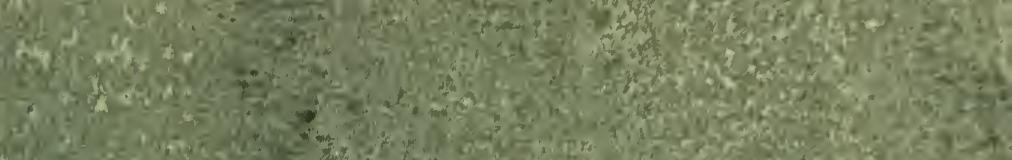

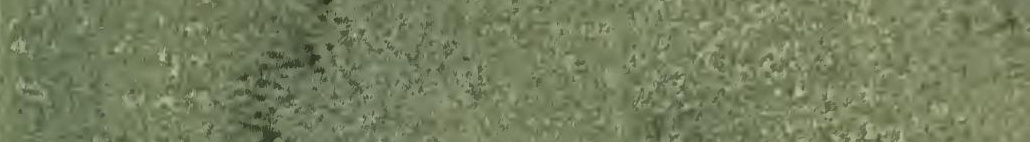

$2 x^{2}+2+23$

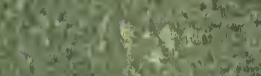

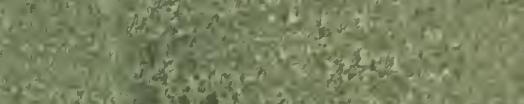

4. 4 रो

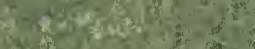

If ond

Nom

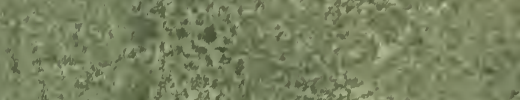

4.

$y^{2}+2 x$

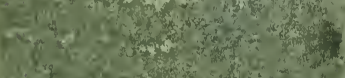

e.

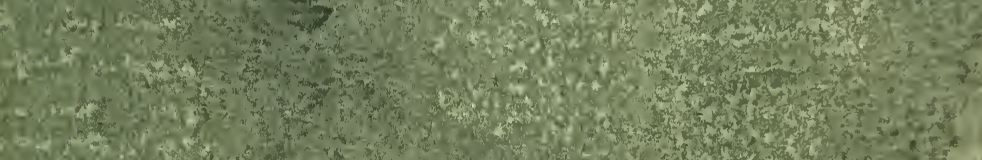

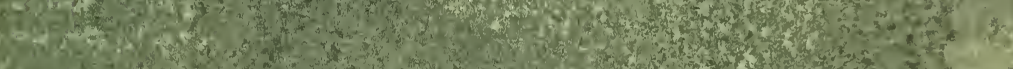

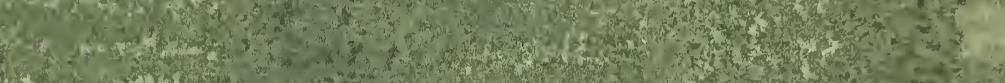

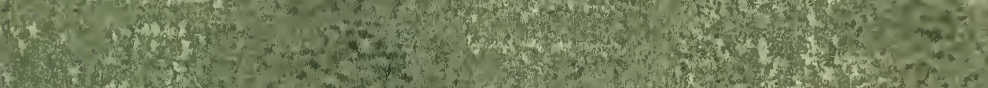

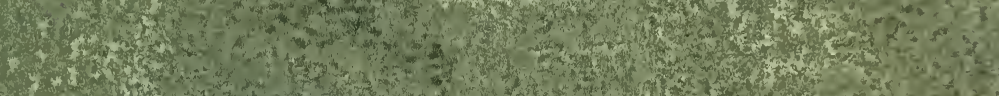

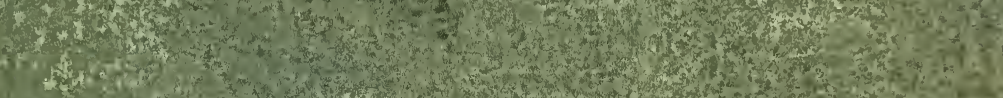

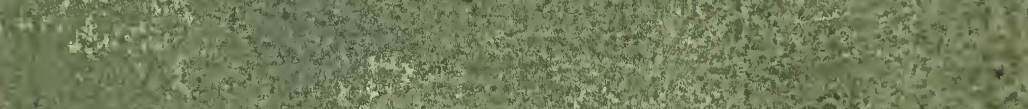

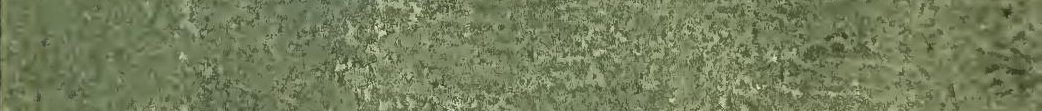

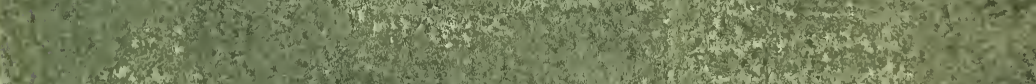

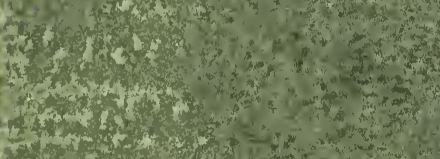

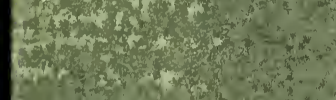

1.

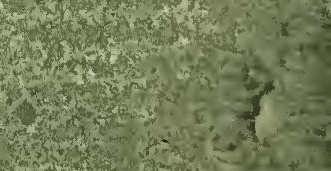

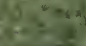

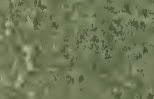

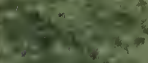

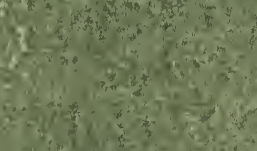

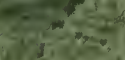

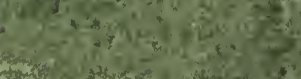

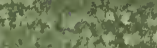

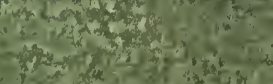

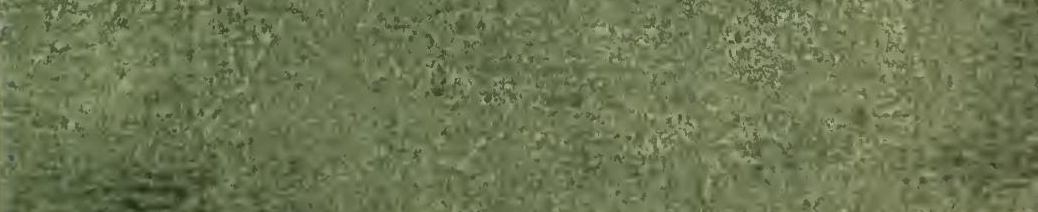

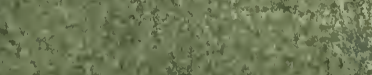

W.

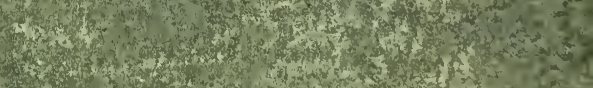

$2 \frac{60}{4}$ 



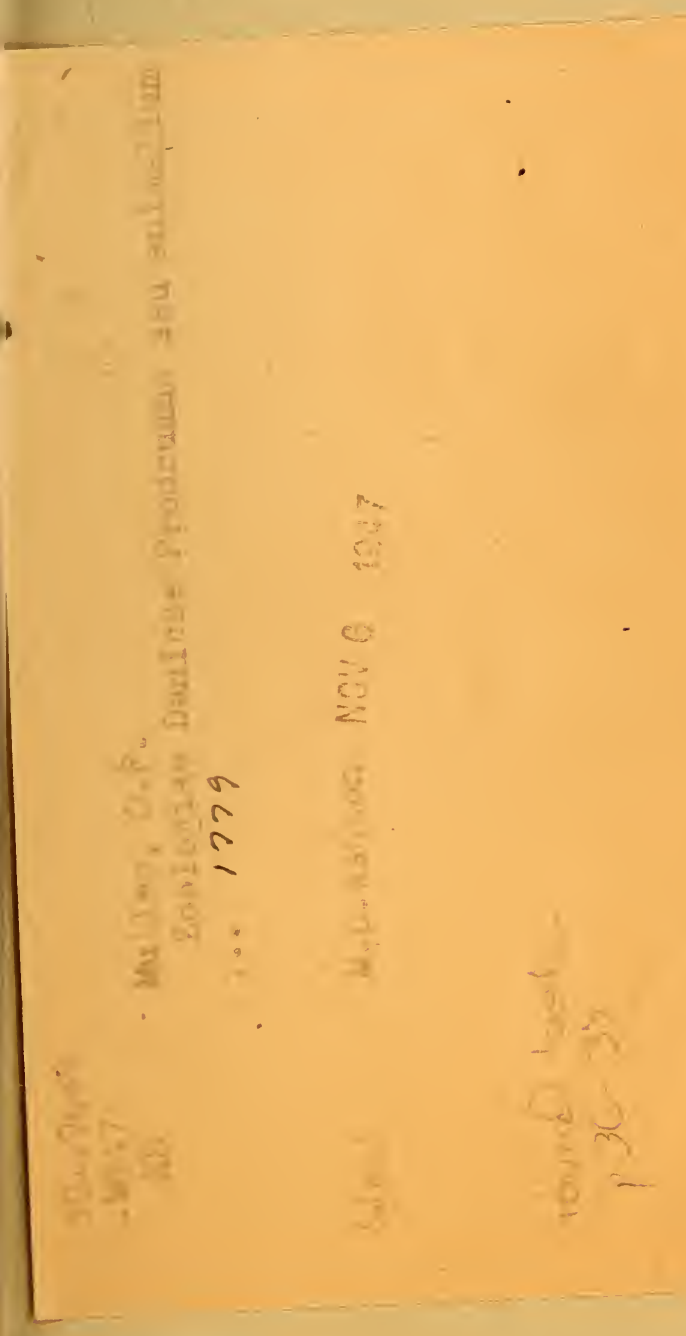





Sxkib. de Staininith 


\section{ZOOLOGIA DANICA $S E V$ $\triangle N I M A L I V M$}

DANIAE ET NORVEGIAE RARIORVM AC MINVS NOTOR VM DESCRIPTIONES ET HISTORIA.

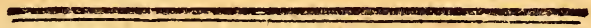

VOL VMEN PRIMVM.

EXPLICATIONI ICONVM FASCICVLI PRIMI EIVSDFM OPERIS INSERVIENS.

A V C T O R E

\section{OTHONE FRIDERICO MÜLLER,} REGIDANIAE A CONSILIIS STATVS,ACAD.SCIENT.ET CVR. EONON. HOLM. ET BOICAE, HAVN. NORV. BEROL. BERN. DANTISC. ET LOND. SC. SOCIET. LIT. SCDALI, ACAD. PARIS. CORRESP.

157227

HAVNIAE ET LIPSIAE, S VMTIBVS WEYGANDINIS, MDCCLXXIX. 


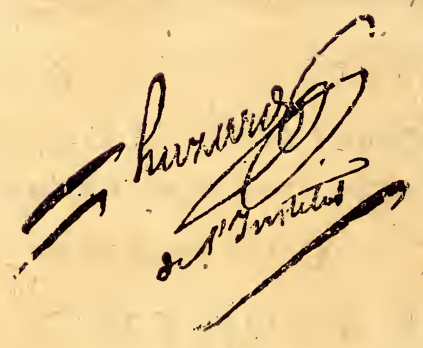




\section{PRAEFATIO.}

Siftuntur hic Zoologis defcriptiones animalium $\mathrm{Da}$ $\mathcal{N}$ niae et Norvegiae rariorum, quorum icones ad viuum expreffas Zoologiae Danicae fafciculus primus dudum in lucem editus exhibet. Lubuit icones et defcrip:iones feorfim formaque chartes diverfa publici iuris facere, ne, quorum res minus lautae effent, animaliuin nofci dignorum occafio ob maius iconum pretium praecluderetur: nec tamen de caritate iconum iure queri quisquam poteft; multi enim eiusdem argumenti libri lónge maioris pretii funt, et quod imagines attinet mea opera publicatas, omnes et fingulae et nouitate et raritate opus nulli fecundum conftituunt. Teftari fimul volui, me abhorrere ab ifta ingrauefcente libidine publicandi icones in pluribus libris decies iam expreffas; hoc enim fcientiam amoeniflimam omnium et maxime neceffariam, cujus acquirendae fubfidia natura cuique ante oculos et in promtu pofuit, tantis fumtibus inuoluir, vt amatores quofcunque absterrere valeat. Limites dehinc mihi praefcripfi, quos vellem quilibet Zoologus fibi ducat obferuandos, ea nempe tantum animalia, quorum vel nulla vel falfa figura exftat, iconibus et quidem ad viuum exprimere et illuftrare.

Fafciculus praefens continet, duobus pifcibus exceptis, non nifi animalia e Vermium claffe, porrentorum feraciffima: pleraque marina, pauca intefinalia, forma, generatione et oeconomia maxime fingularia. Mens haeret, an ingentem figurarum varietatem, an inhaerentem cuiuis genti notas characterifticas, aut cuiuslibet fpeciei differentiales maxime miretur mirabunda vero Numen benigniflimum veneratur. Quae fimplicitas in Fa fciolarum variantibus fpeciebus! 
Quae in Lernaeis admirabilis partium et varia compofitio! Quae in Trichodis et Vorticellis fupenda organorum exilitas! Qualis pompa in Holothuriis! Quae pulchritudo in Loridibus! Quanta organorum profufio in Nereidious! - Deum loquuntur haec omnia, fpectatoremque attonitum reddunt. Me faltern adeo occupauerunc, vt fupta humana erectus, fanitatem ipfamque virarn vili perderem, dum licere rium et finuum percontari, vifceribùs aninalium fpectandis immorari, er cum incolis mundi inuifibilis vfunct confuetuanem habere. Didici dehinc, creatorem optimum omnibus, quas non modo homo fibi fingere poffic ideas, fed ipin rationi aeternae poffibilibus, formam, exifentism et gaudia vitae largitum efle, earumque edypa parim in orbe fublunari, partim in reliquis fphaeris homini indaganda et cognofcenda fepofuiffe.

Naturam et mores horum anima'um parum nofcimus, in fexu ex generationis moco fere omnino ignari; maxima enim ex parte nuperrime innotuere, difficulcatibusque quam plurimis premitur eorundem acquificio, conferuatio et examen; quae tamen in is angutia temporis, aliorum officiorum vices et vita valetudinaria ouferuare permiferunt, hic defcripfi.

Infruinenta, quae in detegendis ignotis animalibus adhibui, pro magnitudine obiecti diuerfa funt: animalium inteftina ope forcipis et ínticulae fimplicis (la loups) perfcrutatus fum; innumeras aquarum gurtulas, ve animalcula fpecifice nofcerem, ope microfcopii perluftraui. Vtroque modo fingulares incolas fuo elemento et fuae habitationi adaptatos inveni; et hic labor nec fumtuofus nec periculofus eft, in ipfo enim muleo commode peragi poteft, naufcofus tamen, fi in vifcera maiorum animalium fiat excur- 
excurfio, vel in aqua foetente perfcrutatio; huius enim gutula, licet animalculorum, viuidorum quoque, plena fit, tancum faepe foetorem exhalat, $t$ t per interualla momento tantum eandem infpicere licue. rit; vifcerum, vt eorum viu indagentur hofpites, per omnes er moleftas inteftinorum ambages mucofasque vermiculorum latebras perquifitio maxime folet effe ingrata. Marina vero inueftigare et maioris laboris et alcioris indaginis eft:

Praecipuum infrumentum, quo fundi maris et finuum incolas extrahere conabar, erat Sacculus reticularis, ex funiculis camabinis concinnarus, margine aperturae alligatus laminis quatuor ferreis ora exteriori acutis, vinam longis, quatuor vncias latis, et in quadratum difpofitis. Angulis laminarum exfurgebant quatuor bacilli ferrei, altera extremitate in annuluin liberum iuncti. Huic annecitur funis ducentarum et plurium orgyarum longitudine. Saccus mari immiffus pondere ferrei apparatus fundum plerumque petit, interdum diuerforum et contrariorum faepe fluminum maris inferiorum aduerfa actione moleque ipfius funis plurium orgyarum in via retineri, nec fundum attingere creditur.

Fundo iniacens ope remorum aut venti modici trahitur, donec tractum quendam quaeuis obuia excipiendo confecerit. In cymbam denique retrahitur fpe et labore, at opera et oleum faepe perditur, nubesque pro lunone captatur, vel enim torus argilla fumante aut imo foetente, aut meris filicibus, aut tefaceorum et coralliorum emortuorum quifquilis impletur, vel faxis praeruptis et latebrofis caucibus implicitus horarum interuallo vel in perpetuum omnia experientis retrahendi inuenta fruftrat; interdum quidem vnum et alterum molhufcum, helminthicum, aut te- 
ftaceum minus notum in dulce laborum lenimen reportat; maria enim regionum frigidarum nec vegetabilibus nec animantibus, vti Zonae temperatiores et calidae fcatent; haud raro enim plures horas absque vlla captura mecum operarii mei impenderunt, cuin vtriusque Indiae finus adeo repleti dicantur, vt remorum motus fucorum et mollufcorum copia retardetur. Huc accedunt aëris intemperies, marisque in finubus et oris maritimis Norvegiae inconftantia adeo praepropera et praepoftera, vt aer calidiffimus vix minutorum interuallo in frigidum, tempeftas ferena in horridam, malacia infida in aefu ferventem pelagum haud raro mutetur. Hanc mutationem faepius cum vitae periculo et fanitatis difpendio expertus fum, nec tamen, membra licet fractus,animum demifi, nec ab incepto defiftere potui. Difcant dehinc hiftoriae naturalis fcituli, rariora naturae absque indefefio labore nec comparari, nec iufte nofci.

In animalibus marinis, quorum enumerationem dedi in Zoologiae Danicae prodromo, conquirendis ma, jorem aeftatis et autumni quatuor annorum partem confumfi, totum nempe finum Chriftianien $/ \mathrm{em}$ ab ipfa vrbe cum adiacentibus plurimis finulis vltra Tönsbergam, dein finum Laurvigen $\int e m$, Helgeroden $\int e m, K r a g e-$ roenfem, Arendalenfem, Chriftianfandenfem, et tractum maritimum intra et extra rupes et fopulos ab vrbe Krageroe ad caftellum Flekkeröen vfque antrorfum et retrorfum percontatus, feptuaginta minimum miliaria minutis portiunculis emenfus fum; quasdam in altum mare excurfiones extra portum Laurvigenfem et Chriftianfandenfem et vltra fcopulos intra Arendal et Rifoer, at cum minori fructu inftitui,finum imprimis Dröbachienfem omni ftudio vel centies colens et recolens. Mare balticum praeterea, qua infulas Daniae $F a l$. 
friom et Lollandiam alluit, finumque Nicopienfem, Nafkovienfem et Rödbyensem, littusque Géfenen $\int e$ indagaui, inde tamen, cum littora ad extenfionem miliaris et vltra mera vada, finufque vix duas vel tres orgyas profundi fint, fructum fere nullum retuli.

Complectitur hoc volumen feptuaginta tres animalium fpecies in maiorem cultorum hiftoriae naturalis vfum latine et qua potui breuitate defcriptas; fequetur danica et germanica editio, quaeuis feorfim, quam primum per alia negotia licébir.

Primus iconum fafciculus defcripta hic animalia quadraginta tabulis aeneis continens, Havniae apud auctorem, Lipfiae apud clarif. Leske hift. nat. et oecon. Profefforem, et Bibliopolam Weygand, Hamburg $i$ apud Bibliopolam Bohn, non coloratus nempe pretio fex, coloribus vero ad viuum pictus duodecim imperialium proftat.

Secundus iconum fafciculus nunc fub prelo fervens, plurima marina, pauca inteftinalia offert, nec vltra tertium fpondeo, cum vires corporis animum indies derelinquant, nec focium aut veftigia prementem commilitonem reperire contigerit. Genera minus nota, quorum plures fpecies in patria inueni, Hydrachnas nempe, Monoculos et Taenias fingulari quodvis opere edere maiori reipublicae litterariae vfui effe reor. In votis quidem adhuc eft, pifcatoribus Bergenfibus, cum retia Gadis, Clupeis et Pleuronectibus capiendis in fyrtibus et collibus fubmarinis arenofis expofta retrahunt, in alto maris adeffe, rariora molluf $c a$ et Cellulana fimul inhaerentia occupaturus, at hancce voluptatem aliis, quibus aes triplex circa pectus erit, concedere cogor. 


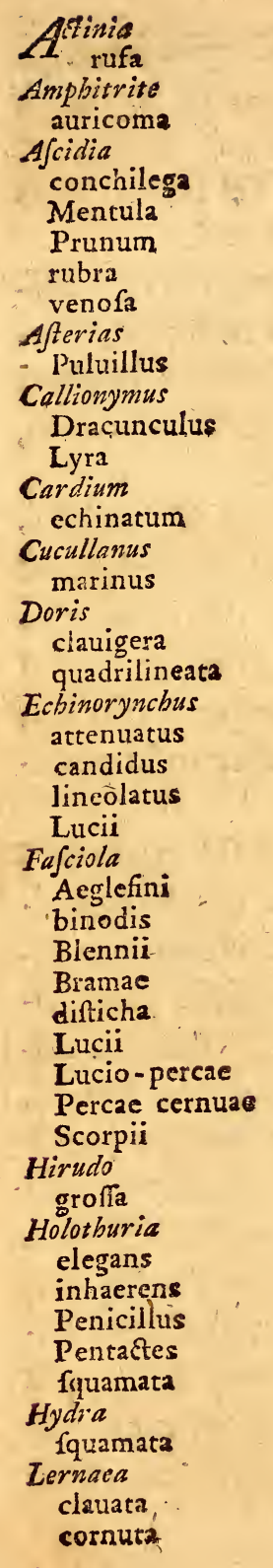

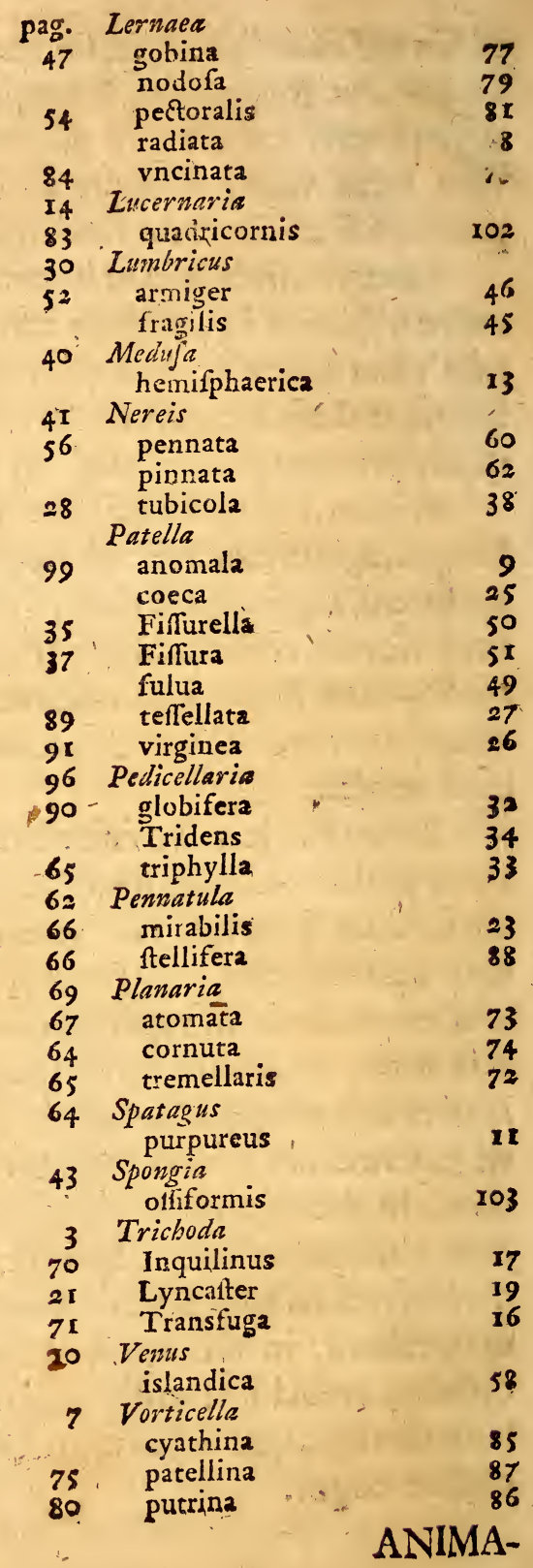




\section{A NIM A L IVM}

\section{DANIAE ET NORVEGIAE}

RARIORVM ACMINVS NOTORVM

H IS T OR I A. 



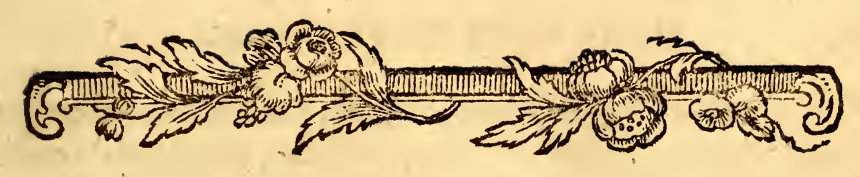

\section{Tab. I. II. III. \\ HOLOTHVRIA ELEGANS.}

HOLOTHVRIA tentaculis viginti racemofis, 1 corpore papillofo, fupra rubefcente, fubtus aibo. Zool. Dan. prodr. n. 2804 .

Ström. Söndmör I. pag. 205.

Gunn. A\&t. Stockh. 1767, t. 4, f. 3 .

Dan. den Smukke Strand-fpröyter.

Norv. Söe - mige.

Long. 8-1 I vnc. diam. max. is - 3 vnc.

corpys fubcylindraceum, elongatum, fupra conuexum, rofeum, papillis acuminatis albis, maioribus ferie fextupla remotis raris, minoribus fparfis; fubtus planiusculum, album, papillis depreffis.

APERTVRA ORYS infra verticem flaua, peripheria rubra, lineisque diametralibus inftructa, fimbriaque papillis acutiufculis cincta.

TENTACVLA viginti, racemofa mihi videbantur ét fubfufca, vix apice plana, retractilia et exfertilia, os centrale ambientia.

APICE EXTREMITATIS oppofitae apertúra circularis; quam fenfim dilatari et corripi, bullasque aereas in viuo animali, aquam vero nunquam, ne quidem in preffo et in agua demerfo, emittere vidi; huic aperturae calamum immittere potui.

c v т Is externe in altero fpecimine punctis minimis rufis adfperfa erat, fafciae mufculares fimiliter in vtro. que. Vtrumque poft paucas horas in aqua marina pe- 
riit; id quod plurimis marinis euenit, forte ob mutatum aquae ftatum. Dum forcipe fecarem, cutis mihi tendinea, craffa et duriufcula fentiebatur, ab interiori latere glabra, transuerfim friata, friis fubtilibus, taeniisque feu fafciis latis quinque laeuibus longitudinalibus aequaliter diftantibus; hae fulco medio cuti affixae, latere vtrinque liberae funt; qualis in figura I, tab. VII. Bohadfchii fiftitur; hae taeniae mufculorum munere funguntur corpus Holothuriae contrahendo et extendendo.

INTESTINVM rectum, craffum, teres, a pariete cutis liberum; triplici ferie longitudinali interiora occupat; excrementis terrenis refertum, nigrum; vacuum, album et pellucidum; fulua et gelatinofa fubftantia paffim obductum; huic longitudinaliter adiacet aliud vas hyalinum paffim in in embrana tenui vafcula fubramofa emittens; hoc in Bohadfchii Hydra liquore viridi repletum dicitur. Inteftina coeca fuperne fafciculatim varie ramofa et lutefcentia abfque punctis rubris oefophago adhaerebant. Pinguedo ramola lanuginis albae inftar inteftino incumbebat.

In ipfa fauce anmulius articularis albus, haud obfcurus; vix dentatus dici poteft nofter; huic introrfum annexa funt tentacula, extrorfum filanenta acuminata alba; in noftra nec punctata nec maculata. Ab annulo dependere videtur veficula pellucidiflima, oualis, fubtiliffme friata; in fundo veficulae tránsparet lapillus albus.

In maiori exemplari inteftina coeca atomis fphaericis farta vidi; an ouaria? alia corpufcula fphaerica alba illis maiora gelatino hyalino folito cincta paffim circa inteftina reperi; an ovula? Tentacula cylindrica alba, apice marginali racematim fiffa; laciniae intrórfum tuberculis minimis fufcis obfitae, extrorfum nudae.

Corpus

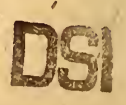


Corpus inflare, et pro lubitu attenuare valet.

Defcriptio Holothuriae tremulae Linnaei et Gunneri A ZZ. Stockh. $17 \sigma_{7}$, t. 4 , f. 3 , noftram fiftit; figura vero nimis rudis eft ; nec eadem, quamuis ita Linnaeus' ait, cum Bohadfchii Hydra eft; nec motum tremulum vnquam vidi. Manu prehenfa aquam e foramine poftico tanquam e fiphone vltra tres vel quatuor vlnas proiicit, quod mihi fpectaculum omnes praebuerunt; aquae vero immiffa nulla, mihi faltem, aquam vibrauit.

In finu Dröbachienfi, anno 1774 , in fundo pifcium multitudine celeberrimo Stormeien, duas fimul 80 orgyis femel extraxi; fefe inflare et aliquantum contrahere, excrementa quoque e parte tentaculis cincta excernere vidi; an vero merus limus ori adhaerens effet, an vera excrementa, haereo; haec tamen effe, perfuadere videtur contra auctorum fententiam defectus connexionis inteftini cum apertura poftica omnis.

Anno 1775 maius fpecimen expifcatus fum; hoc mihi phaenomenon maxime fingulare Bohadfchii confpiciendum praebuit; totum enim inteftinum craffum cum oefophago et adhaerente pinguedine excreuit; inteftina vero coeca et veficula annulo appenfa remanfere; haec in nouo fpecimine hyalina, absque omni fria, ouata, vnco appendiculata; nec vllus in hac lapillus adfuit; illa filamenta tenuiffima inaequalis voluminis.

A Bohadfchii Hydra praecipue differt, quod nullis omnino tentaculis cylindricis ventralibus inftruatur, quod veficam habeat etc.; plura tamen communia habent.

Mentula marina Planci conch. t. 8. f. A, B, et aliorum noftra effet Holothuria, quantum ex prauis figuris coniicere licet, nifi obftarent glandulae perforatae vifco- 
fum humorem excernentes, quae in noftra minus obtinent; lubentius erit Hydra Bohad/chii, in qua tubuli ventri perforati confpiciuntur. Inteftina fponte ex ano procidere, ante Bohadfchium, Planco, Rondeletio et Redi faltem innotuit.

Holothuria tremula Chinenfium palato grata dicitur. Pall. Peifen 3 Th. S. 109.

Plures figura maiores, quaedam minores funt. conf. Vand. diff. p. 89. t. 3, f. I, 2, 3 .

Noftris accedunt Fiffularia maxima Forfkahlii t. 38 , f. B. et impatiens t. 39 , f. B ; t. 39 , f. A vero tremulae Bohadfchii affinis eft. Aquam longe diuque tanquam ex fiphone proiicere recte meminit For $\int k a k l i u s$, foramen pofticum vero hallucinatione pro ore fumfit.

Tab. I. Totum animal naturali magnitudine monftrat.

Tab. 2. Interiora animalis, fafcias, nempe cutis mufculares, inteftina, inteftinula feu ouaria, vafcula pinguida, veficam, maxillam àd dextram et tentacula ad finiftram exhibet.

Tab. 3.f. I. Intentina, quo fitu per foramen pofticum in agone mortis explofa funt.

f. 2. Veficam fingularem.

f. 3. Vafa pinguida prout e foramine poftico protrudebartur, aucta magnitudine. 
Tab. IV.

\section{HYDRA SQVAMATA.}

HYDRA coccinea, capite mutabili vndique cirrato. Zool. Dan. prodr. 2586.

Mollufcum $\mathfrak{B}$ erl. $\mathfrak{B}$ efd). r. t. 5, f. 3, 4. p. 406.

Hydra multicornis nuda, clauata, tentaculis 14 fparfis, fubulatis. For fkahl, anim.p. I 3 1, t. 26, f. B, b.

Dan. Skael - polypen.

Animalium, quae Zoophyta dicuntur, nullum elegantius, obferuatorique magis gratum effe poteft.

CAPVT coccineum pinnis feu cirris albis 6-1 5 fparfim ornatum; pedicellas quadruplo capite longior albus, fquamis orbicularibus caput verfum varie et aceruatim obfitum.

Ope microfcopii ex materia mucida fucum veftiente ortum fumere videntur; fubftantia gelatinofa; pedicellus albus pellucidus, cuius medium percurrit medulla rubra in ipfum caput producta; hoc quoque albedine pellucida cingitur, et varias formas induit; vel enim clavatum apice acuminato, curuato aut orbiculari, vel adeo retrahitur, "vt merus orbiculus coccineus confpici poffit. PINAE e capite prodeuntes pellucidae albae, pro lubitu animalis vel extenfae anguftantur, vel aliquantum retraEtae incraffantur et curuantur, apice paffim fubglobofo.

SQVAMVLAE in vnicum acervum iuxta bafin capitis, in quibusdam in duplicem, alterum in pedicello parumper a bafi remotum, congeftae maximam attentionem merentur; eiusdem fubftantiae cum Hydra, albae, 
pellucidae orbiculares, medio linea perpendiculari rubra; feffiles videntur et reuera pedicello minimo ftipiti adhaerent. Oua, an gemmae effent diu dubius fui, donec, vti furpicabar, in fuco deciduas progerminare viderim.

Squamae in exemplari Havnienfl et in For Skahlii defuee ; oula enim non omni tempore adfunt. Inter fucos ad fundum maris inueniri dicitur, rectius in ipfis fucis verfus fuperficiem aquae fluctuanitibus.

In fuco veficuloso raro in littore Wennebech Chriftianienfi, ac in palis portus Havnienfis reperi.

F. I. Congeriem in frufto fuci veficulofi naturali, f. 3 . aucta magnitudine f. 2. ouulaque valdè auta exhibet.

Tab. 
Tab. V.

\section{PATELLA ANOMALA}

PATELLA tefta rudi, fufca, orbiculari vertice fubmarginali. Zool. D. prodr. 2870 .

Dan. Haar - Kröllen.

ANIмALCvevm ab inhabitante patellarum limace toto coélo diuerfum, tefta vero generi conuenit, fubftantia tamen penitius infpecta aliquantum diuerfa eit.

TESTA integra fuborbicularis, extus fcabra, inaequalis, variolofa, fufca, vertice marginem verfus pofito, fubacuto, integro, intus albido-caerulefcens foueolata, oculo armato confertim punctata.

Vermis fingulariffimus conftat lobis duobus fpiralibus feu cincinnis binis carnofis, albis, fimbria ex cirris capillaribus confertiffimis, rigidiufculis cinctis. Hi cincinni anneetuntur funiculo duplici caerulefcente, teftae et faxo adeo adhaerente, vt ab vtroque non absque dilaceratione, remanente femper in tefta et in faxo aliqua corporis mole, auelli queat.

Cincinno quaelibet ramificatio fufca cornua damae referens tegitur; in ipfo lapide, tefta auulfa, refidua ouúlis flauicantibus vndique obfita confpicitur.

Hanc effe Nummum Brattensburgenfem auctorum, $\epsilon o n f$. Fn. fu. 1347 , ed. 1746, ex adiectis figuris verofimile videtur, at ille biualuis eft.

In faxis et teftis biualuium paffim; primo afpectir et tactu inaequalitates lapidis, cui infident, non teftaceum quid crederes. 
Fig. I. Saxum tribus patellis paffim obfitum ac vnius ouaria ramola derelicta, teftamque Serpulae ac fruftum Nilleporae polymorphae exhibet.

Fig. 2. Faciem exteriorem

Fig. 6. interiorem patellae

Fig. 3. vero ipfum inhabitatorem naturali magnitudine offert.

Fig. 4. Animalculum cincinnatum ligamentis et mufulis teftae adhaerens aduerfa parte aúcta magnitudine monftrat.

Fig. 5. lobos firirales cirratos e tefta euulfos anerfa parte exhibet.

Fig. 7. ouaria ramofa mufculorumque veltigia aucta magnitudine.

Fig. 8. ouula maxime aukta: 


\section{Tab. VI.}

\section{SPATAGVS PVRPVREVS.}

SPATAGVS cordiformis, fpinis maioribus raris albis. Zool.D. pr. 2850.

Dan. Purpur - Hiertet.

Echinites cordatus vuigaris. Luid. 964 .

Echino-Spatagus cordiformis; marino-terre:

Atris, anglicus. Breyn. Sch. t. 5, f. 5,6 .

Spatangus purpureus. Leske additam. ad Klein echinod. p. I7 I. t. 43 . f. 3, 4, 5. t. 45 . f. 5 .

Hic inter pulchriores locum obtinet, dum in vivis natiuo colore et fpinulis varii voluminis vndique obfitus fpętatur. Figuram cordatam exąte fiftit.

Supra conuexus fulco verticali, ftriaque laterali bicrura ex minimis fpinulis vtrinque deflexis conflata; maiores fpinae leu aculei confertiffimi deorfum deflexi; maximi feu longiffimi acutiffimi, deorfum curuati, plerumque quinquefariam fparfi funt; -hi albiffimi, reliqui purpurei coloris funt. Subtus planiufculus fpinulis acutis inter maiores et maximas mediis vtrinque obfitus; difco vero aculeis obtufis feu fubfpathulatis diuergentibus ornatus; minus enim fpathulati et compofiti funt quam in Spatago flauefcente Zool. D. prodr. 2849. Os fubtus rima transuerfa, 26 penicillis purpureis mobilibus cincta. Anus in margine poftico.'

INTERANEA nulla omnino alia, quam inteftinum ratum, et fafciculi tres molecularum albarum, qui vel ouaria vel miram pinguedinem conftituunt. Inteftinum conftat tunica fubtilifima, mera terra vndique farta $a b$ ore feu rima teftae media per tres anfractus totum interius occupantes ad anum productum. Ouaria ope funiculi 
niculi medio dorfi adhaerere videntur. Tentaculorum nulla veftigia. Sola foramina confpexi, haec tamen tentaculis minimis producendis et reducendis inferuire nullus dubito.

Purpureus color in mortuo verme in grifeum transit.

Huius petrefacti icon paffim aere incifa exftat, naturalis vero nullibi, nifi in additamentis ad Kleinii echinod. quae eft haec noftra recufa. Aculeis et fpinulis orbatus paffim, iisdem vero inftructus rariffime in Mufeis occurrit.

In finu Dröbachienfi ad infulam Kaholm raro.

Fig. I. Spatagus pronus naturali magnitudine.

Fig. 2. Aculeus dorfi maximus amplificatus.

Fig. 3. Spatagus fupinus naturali magnitudine.

Fig. 4. Aculeus fpathulatus cum nodulo, in quo mouetur, amplificatus.

Fig. 5. Tentaculum penicilliforme valde anctum. 
Tab. VII.

\section{MEDVSA HEMISPHAERICA.}

MEDVSA coftis transuerfalibus quatuor, tentaculis globulisque marginalibus, margine integerrimo. Zool. D. pr. 2822 . Linn. fyst. 1098, 9. Act. helu. 4. P. 38, t. 4, f. 7 .

Dan. Kalot-goplen.

Diam. 2 lin.

Animalculum fingulariffimum, difficulter detegendum, adeo pellucida et hyalina eft materies, ex qua componitur, vt nec nudo, nec armato oculo vllo modo interdiu videatur; nudis oculis ex folo motu viuum ouid agno. fcitur, armatis globuli, ligamenta et filamenta confpiciuntur. Materies ipfa ad lucem nocturnam primum in confpectum fubit ope microfcopii, ac punctulis minimis conflata cernitur. Hemifphaeriumeft, vertice quadrato (in quo aliud minus quadratum flaum) inftructum; a quovis huius angulo defcendit ligamentum ad peripheriam vfque; ligamento adhaeret corpufculum ouatum aliquantum a peripheria remotum, ac in ipfa peripheria globuli fedecim flauicantes filamento fexuofo pendulo inftructi. Infra, peripheriae annexae funt laciniae intus vergentes, ipfique vertici fubtus affixum eft organum quadrilobum mobile. Filamenta feu tentacula dicta reEta extendi et corripi poffunt.

Motus in Medufis folitus, contratilis, et extenfilis, feu periftalticus totius corporis.

In finu Dröbachienfi rariffima.

Fig. I. Medufam naturali magnitudine, reliquae ampliatam fiftunt.

Fig. 2. a latere vifam.

Fig. 3. fupernam fuperficiem in dilatatione.

Fig. 4. infernam in contractione, ac

Fig. 5. tentacula valde aucta exhibet.

Tab. 
Tab. VIII.

\section{ASCIDIA MENTVLA. .}

ASCIDIA compreffa pilofa, facculo rubro, aperturarum altera laterali. Zool. D.pr. 2724 .

Mentula marina; pudendi marini altera fpecies.

Mentula marina. Ionft, t. 20 , f. 2.

$$
\text { Gefn. p. I } 54 \text {, f. I. }
$$

Pudendum alterum. Rond. pifc. 2. p. 129.

Dan. Nyre-Söe - pungen.

Isl. Konu pungur.

Germ. Meer - Schaam.

Gall. Le vit de mer.

Afcidiarum fingulariffima. Maffa informis cinereoflauefcens quadratum irregulare fittens; fubftantia craffa gelatinofa, duriufcula, fubpellucida, reiectamentis corallinarum et fucorum paffim obfita.

APERTVRAE binae (faepé obfoletae) mammillaeformes, pallide rubentes punctis fparfis fanguineis centrum verfus corrugatae; pro figura maffae, quae $a b$ adiacentibus corporibus determinatur, vel vtraque lateralis, vel altera plerumque terminalis.

IN TERANEA conftant facculo carnofo, rubro, vacuo, vndique libero, aperturis parte productiore inhaerente; altero facculi latere incumbit maffa oualis albicans, pinguedine farta, membrana fubtilifima cincta, ex pellucenti intertino colorem luridum exhibens. In iplo inteftino aliud inteftinum reperi; hoc vacuum, illud vero moleculis-terrenis circa inteftinum medium repletum erat. Alterum facculi latus ruberrimum lineolis albis fparlis ornatur. 
Bina fpecimina reperi; in alterius cute tria indiuidua Mytili dificordis nidum fibi fecerant, feu potius gelatina pellucida inuoluti erant, viui adhuc et quafi absque moleftia, fingulari fatis phaenomeno. Cultro gelatinami diffecui, Mytilumque pulcherrimum, rariffimumque, qui fefe ligamentis capillaribus cuti affixerat, extraxi. Alteri extus infidebat Afcidia iunior coccinea.

Haec in mentem reuocat Microcofmum marinum Redi in actis erudit. 1686 . p. 48. t. 2. f. I. expreffum, quem vel noftram Afcidiam vel congènerem effe fufpicor.

In finu Dröbachienfi circa infulam Haä̈en.

Fig. I. Afcidiam integram cum infidente iuniore exhibet.

Fig. 2. eandem fecundum longitudinem diffectam, faccur lum dehinc et maffam oualem inteftinorum.

Fig. 3. foueam in cute cum Mytilo ex eadem deducto.

Fig. 4. Specimen diuerfum, diffectum, vt alterum facculi latus lineolis albis infcriptum appareat.

'Tab. 
Tab. IX.

\section{TRICHODA TRANSFV $=$ A.}

TRICHODA latiufcula antice crinita, putice. fetofa, altero latere finuata, altero mucronata. $Z \cup\urcorner$. D. pr. p. $28 \mathrm{I}$.

Dan. Spring - Spilleren.

Animalculum nudo oculo inconfpicuum, oblongum, pellucidum, interaneis indiftinctis; fupra ad medium vfque et vltra conuexius, dorfo interaneis vacuo, poftice in membranam latiufculam, depreffam et quafi productam; haec truncata eft, caudaque dici poteft, alterque eius angulus in breuem cufpiden producitur. Subtus e cauda propendent fetae quatuor vel plures curuatae, pediformes, vix vltra finem caudae porrectae. Altero margine prope caudam coarctatur corpus ipfum, altero finuatum eft, apice vero pilis breuiffmis ludentibus, duos interdum fafciculos momento confituentibus inftruitur.

Dorfo plerumque, interdum ventre mouetur; parumper lente glifcit, mox vero corripitur et aliquantum recedit; reiteratur proceffus et concitatum refugium. Haud raro correptione ope fetarum pofticarum e confpectu et quafi in aërem feu extra guttam fubinde $a b$ vna ad alteram guttae plagam aufugit.

Huius quaedam indiuidua mihi copula iuncta vifa funt: antica pars adeo pofticae alterius incubuit, vt frons alterius, qua parte finus confpicitur, affixa effet, ficque firmiter cohaeferint. Poft feparationem organum quoddam porrectum momento temporis conipiciebatur. 'Coniunctorum fitus vix diuifionem transuerfalem indicare poterit, dimidium enim anterioris animalculi corpus, feu poftica pars anticae pofterioris parti fubiacebat *). Natatus in copula et in inftanti diuifione in animalculis aeque perficitur.

Fig. I. Quinque Transfugas, primum fupino, fecundum et tertium prono fitu, quartum et quintum copula iunEum exhibet.

*) Hoc licet faepius viderim, penitiore tamen indagatione et meliori microf́copio dignum eft. 


\section{TRICHODA INQVILINVS.}

TRICHODA vaginata, folliculo cylindrico, hyalino, pedicello retorcili. Zool. d. prodr. 28I.

Dan. Lögte-Spilleren.

Inter minima animalcula haec eft, opeque lentis No. 4 fimplicis microfcopii oculus tantum punctulum mobile percipit.

Foncicvurs feu vagina ouato oblonga, teres, hyalina, adeo pellucida eft, vt maxima amplificatione margo tantum linearis et quidem oculo obferuationibus inuifibilium adfueto percipi queat. Huic innatum eft animalculum, quod vor TiCELlam pedunculatam dici crederes; donec defeetus rotationis ciliorum ac micatio pilorum in Trichodis folita hoc animalium nouitium his vindicaret, licet re vera ob pedicellum inter vtrumque medium fit.

CApitvivm crateriforme moleculis obfcuris repletum, apice halone forte ex rotatione ciliorum occulta cingebatur; haec aliquamdiu ne armatis, quidem oculis percipere potui, poftquam vero in maioribus fefe conpicienda praebuere, pilorum nomen aptius conuenire ob micationem absque rotatione videbatur. Saepe organum pilorum pectinis inftar dilatatur, tum dentes extremi diftinctiores nigricantes, medii vero gelatino hyalini, quilibet varie mobiles, videntur.

PEDVNCVLVS hyalinus medium vaginae percurrit, bafi interdum lateriaffixus; quoties contrahitur, pili conduntur, capitulum demergitur, ac lineae laterales vaginae tanquam fetae porrectae proftant. Lente capitulum rurfus exfurgit, pilis feu tentaculis rarioribus in itinere paffim porrectis, demum oftium vaginae occupat, nutri- 
tioni intentum pilos motitans. Hoc quoque intra vaginam moueri apicemque capitis porrigi vidi.

Motum circa puluifculum, cui plerumque adhaeret, lentum ciet; vel capite in extremo vaginae haerente, ope pilorum, vehementer circumnatat; vel bafi vaginae, nefcio quo medio, cum glaberrima fit, in gutta affixum, vel perpendiculariter vel oblique porrectum, motum in aqua continuum ac correptionem apicis capituli alternam profequitur.

Duas fecundum longitudinem connatas offendi; bafis vaginae fuperioris feu anticae, apice inferioris impofita erat, ac haec ab illa in omnem fenfum trahebatur: tandem antica fefe a poftica diuellebat.

Quasdam vidi, quarum capitula triplo maiora erant, ac totam fere vaginam occupauerant pedicello vel inconfpicuo vel breui; vaginam quoque binis animalculis habitatam cum fuis pedicellis.

Propagatio dehine peragitur, dum animalculum craffius folito factum, medio transuerfim diuiditur, bafisque anticae partis pedicellum, pofticae vero organum pilorum explicat, quo vero medio vagina difpefcatür, haud concipio.

In aqua marina recenti et pura, etiam in non renouata tota fere hyemé 1776,1777 et 1778 .

Fig. 2. Inquilinum nouies vario fitu fiftit; fquamulae vaginae in quinta figura adhaerentes funt Monades cohabitantes. Series fecunda matres grauidas feu potius inftanti divifioni maturas, ac vltima figura matrem in duo animalcula iam enatam. 


\section{TRICHODA LYNCASTER.}

TRICHODA fubquadrata, roftro obtufo, difco pedicellis micantibus. Zool. d. prodr. $28 \mathrm{I}$.

Dan. Glimmer-Spilleren.

Prima facie valde refert Trich. Lynceum, Verm.terreftr. et fuuial.87., fatis tamen, praeterquam marina, diuerfa eft; oculo nudo inconfpicua, nec ante elapfum menfem in aqua marina feruata mihi obuenit.

Corpus membranaceum, fubquadratum, compresfum, bafi poftice productum, antice mucrone auctum, medio truncatum fetis paucis porrectis : apice fubroftratum pilis fub roftro raris. In aduerfa corporis parte lineae duae longitudinales curuatae, ac tres feries pilorum pediformium micantium transuerfales, globulo mobili articulatorum; pars auerfa vero pilei inftar medio in colliculum pellucidiffimum eleuatur, ora dilatata.

Inceffus fit vel vacillando in ora corporis acuta, vel lente et interrupte in corporis conueza parte glifcendo.

In aqua marina diu feruata haud frequens.

Fig. 3. quatuor Lyncaftros monftrat, fecundum in moti vaeillante. 


\section{Tab. X.}

\section{HOLOTHVRIA SQVAMATA.}

HOLOTHVRIA tentaculis oftonis fubramofis, corpore fupra fabro, fubtus molli. Zool. d. prodr. 2810 .

Dan. Skael -Strand - fpröyteren.

Inter Patellam, Aficidiam et Holothurian et Doridem ambigere videtur, characterem cuiuslibet fimulans.

Prima facie Pateliam mencitur, eius enim inftar faxis adhaeret, tegumento duro, fquamulofo conditur, faxoque foluta, fuperficies infima Mollufcum glabrum, qualis pes in Limace, papillis minimis cinctum prodit; penitius infpicienti in fuperficie conuexa binae eleuationes remotae, aperturas Afcidice reuocant; denique patientiori indagatori altera eleuatio aperitur, octoque tentacula alba pinnatifida fefe pandunt, proque lubitu fingulatim mouentur, ideamque Afinime reuocant. In altera eleuatione nullam vnquam aperturam detexi, etiamfi eandem fufpicatus effem, fquamulas tamen fecedere, areamque nudam apparere, ac efforefcentiam vti Dorides minari, rurfusque recedentibus fquamulis tegi, rariffime vidi.

Armato oculo puncta albida, fparfa in fquanulis confpiciuntur.

Saxis finuum Norvegiae adhaeret haud frequens; fimile Mollufcum oui gallinacei magnitudine ex infulis Curilicis accepiffe in litteris refert clariffimus Pallas.

Fig. I. Holothuriam Syumatam fuperne vifam naturali magnitudine claufisque aperturis.

Fig. 2.- eandem, tentaculaque explicita, aucta magnitudine.

Fig. 3. eandem inferne vifam naturali magnitudine. 


\section{HOLOTHVRIA PENICILLVS.}

HOLOTHVRIA tentaculis racemofis octo, corpore offeo pentagono. Zool. d. prodr. 2 SO\&.

Dan. Penfel-Strand - fpröyteren! referens,

corpys inuerfe conicum, penicillum non inepte

TENTACvLA racemofa, fafciculata, granulofa, lutefcentia odto.

COLLARE/fufcum margine vtroque nigro, pone collum annulus granulofus pallidus.

Corpvs feu truncus albus, angulatus, glaber, car tilagineus, decem quafi tigillis longitudinalibus offeae fubftantiae compofitus; horum alterni bafi feu iuxta collare lobo carnofo pendulo inftrunntur, a medio ad apicem vsque fulco cauati funt, alterni bafi vtrinque foffula notati, medio abrupti funt. Apex omnium corpore fubfphaerico carnofo luteo, vertice perforato terminatur.

In fedimento argillofo finus Dröbachicenfis femel tantum reperi, an vero integrum fpecimen, an Holothuriae pars fit, nondum mihi perfuadere potui.

Fig. 4. Penicillum, qualem inueni, exhibet. 


\section{HOLOTHVRIA FVSVS.}

HOLOTHVRIA tentaculis denis, corpore fúf formi tomentofo. Zool. d. prodr. 2809 .

Dan. Spindel-Spröyteren.

Corpus teres, antice et poftice acuminatum, molle, grifeum, fquamulis minimis fubrugofum, filis breuiffimis flocci inftar vindique veftitum. 'Altera extremitate rarisfime protruditur (in pluribus enim femel tantum contigit) corpus infundibuliforme, cauum, quod os et oefophagus, bafi attenuatum apice dilatatum, orbiculare, margine tentaculis pinnatis decem, binis abruptis, cinctum, centro perforato. Altera in quibusdam, in aliis medio corporis protruditur fafciculus filamentorum luteorum, quae pellucida funt et ferie ouulorum repleta, hinc ouarium.

In argilla finus Dröbachienfis vltra 60 orgyas, cum Holothuria Penicillo.

Fig. 5. H. Fufum tentaculis porrectis et vafculis oniferis protrufis naturali magnitudine.

Fig. 6. Os, oefophagum, tentacula octo integra, duo ab. rupta, aucta magnitudine fiftit. 
Tab. XI.

\section{PENNATVLA MIRABILIS.}

PENNATVLAA ftirpe filiformi rachi diftiche pennata : pinnis lunatis remotis alternis. Linn. Syft. p. I312. Zool. d. prodr. 3074.

Pennatula fimplex alba, calyculis recuruis alternis, octodentatis. Pall. Zooph. 216.

Polypus mirabilis. $M u$ f. Ad. Fr. p.96.t. 19. f.4. Amoen. acad.4. p. 257.

Att. angl. 53. t. 10. f. 17.

Dan. Straae-Söe-fiaeren.

Long. $3-16$. vnc. diam. $\frac{x}{4}$ lin.

Haec animalculorum potius concatenatio, quam animal, ante me a nemine viua vifa eft, quantum ex defcriptionibus et figuris auctorum colligo; Linnaeus et Pallas cadauer in Mufeis Regis Sueciae et Principis Araufionenfis examinarunt; ille idem in $M u f e v \mathrm{Ad}$. Fr. pingi curauit, et Ellis ex hoc in Act. angl. figuram transtulit. Hinc defcriptio in Amoenitatibus et in Mufeo aeque curta et minus accurata; in hoc enim dicitur feta filiformis, rigida, femipedalis, cui infident alternatim lunulae ciliares, gelatinofae albae, omnes ad alterum latus verfae, in illis Pennatulae phosphoreae admodum affinis, alba, cum reuera a phosphorea toto coelo diuerfa fit; foloque officulo aliquatenus conueniat. Clariffimus Pallas dehinc ambigit, an non potius Gorgoniis annumeranda fit; offculum calcareum vero, parenchyma carnofum ac $\mathrm{Hy}$ drae diftinctae eam Pennatulis vindicant.

RACHrS feu officulum teres, aequale, longum, vtrinque truncatum, flauefcens, flexile in fpirales in recenti ftatu absque fractione, inueteratum vero cum talitro frangitur, eburneo haud abfimile. Parenchyma carnofum rufum totum officulum inueftit, fummo apice exB 4 cepto, 
excepto, ac ab apice ad bafin vsque in laminas lunatas concolores et polypiferas alternatim efflorefcit; margo laminarum, qua apicem fpectat, Hydris cylindricis octo, et quaelibet totidem tentaculis inftruitur.

Officulum calcareae, epidermis vero et laminae polypiferae, carneae et gelatinofae fubftantiae funt.

Bafis feu extremitas fundo argillofo infixa ex parenchymate carnofiori feu lamellis, quarum Hydrae nondum euolutae funt, craffior ac vtrinque ferrulata eft; in diftantia tamen dimidiae vnciae iuniores Hydrae iam confpiciuntur, ac mox dißtae laminae alternatim e parenchymate enatae vtrinque officulum occupant, $60-70$ a quouis latere. Hinc patet, incrementum officuli et Hydrarum nón apice, fed bafi fieri, et quidem partem officuli et parenchymatis carnofi ante Hydrarum euolutionem ex hoc prouenientium adeffe.

Extra aquam Hydrae fefe contrahunt, ac officulum mera carnofa fubftantia tectum videtur, aquae vero immiffae mox brachia feu laminas et tentacula pandunt; fpectaculum vifu digniffimum. Libere in aqua vagari, quod de congeneribus narratur, minime poffe videtur.

Pennatula Sagitta r.r n ae r huius mera varietas videtur; paulo enim maiores, fimiles faepe reperi.

In finubus Noruegiae, praefertim in Sand-pollen finus Chriftianienfis plurimas cum argilla viuas extraxi.

Fig. I. Penzatulam mediae longitudinis vltra centum Hydris inftructam naturali fitu et magnitudine.

Fig. 2. partem Pennatulae cum Hydris florentibus am: plificatam.

Fig. 3. oficulum parenchymate et Hydris deftitutum fiftit. 
Tab. XII.

\section{PATELLA COECA.}

PATELLA tefta integra, punctis eleuatis friata, vertice acuto, recto, Zool. d. prodr. $2 \$ 66$.

Dan. Blind-patellen.

Tefta obfcura, margine albo, pellucida, ftriis 60 .. 80, ex punctis conuexis a vertice ad marginem percur. rentibus.

Vertex mucronatus, rectus, non recuruus, non prorfus in media teftae fuperficie, fed aliquantum verfus eam partem teftae, quae caput animalis obtegit.

Lisax albidus, tentaculis duobus fetaceis.

Oculos in hac detegere minus potui, etiamfi eos pluries quaefiuerim.

In lapidibus fundi finus Dröbachienfis raro.

Fig. I. Patellan fuperne vifam naturali,

Fig. 2. eandem aueta,

Fig. 3. Limacem cum tentaculis teftae inhaerentem naturali magnitudine monftrat. 


\section{PATELLA VIRGINEA.}

PATELLA tefta integerrima alba, fafciis rubris. Zool. d. prodr. 2867.

Dan. Rofe - Straalen, Jomfru-Patellen.

Tefta alba concentrice ftriata, fafciisque octodecin rubris a vertice ad marginem decurrentibus infignita; intus fafciis pellucentibus concolor.

Mucro verticis a centro aliquantum remotus eft.

Irmax albus tentaculis binis fetaceis; Oculi ad bafin extus. Pallium fubrufum margine integerrimo.

Exemplum maius, quod in figuris exhibetur, rarum; minora vulgaria funt.

In fucis finuum Noruegiae paffim.

Fig. 4. Patellam fuperne vifam,

Fig. 5. eandem inferne Limace foetam naturali magritudine fiftit. 


\section{PATELLA TESSELLATA.}

PATELLA tefta integerrima albida, tefferis rubris. Zool. d. pr. 2868.

Dan. Taerning-Patellen.

Tefta obfcure alba, a vertice ad marginem longitudinaliter oculo armato argute ftriata, maculis fanguineis teffellata; intus concolor 'macula rufa centrali. Mucro verticis obfoletus.

Lrmax albus tentaculis duobus fetaceis; Oculi ad bafin extus. Pallium obfcurum margine ciliato albo. Caput animalis in hac et in antecedente plagam, quam mucro teftae fpectat, occupat.

In fucis cum praecedente.

Fig. 6. Patellam fupinam Limace inftruetam,

Fig. 7. eandem pronam,

Fig. 8. teftam vacuam exhibete 


\section{Tab. XIII. et XIV.}

\section{CARDIVM ECHINATVM.}

CARDIVM tefta fubcordata fulcata, coftis carinatis aculeatis.

Cardium tefta fubcordata, fulcis exaratis linea ciliata, aculeis inflexis plurimis. Linn. Syft. p. II 22. Fn. fuec. 2139 . M.L.V. 486.

Géfner. aquat.

Concha echinata. Rond.

Concha fulcata. Ginann. op. n. 2. p. 24. t. 19. f. 130 .

Peltunculus echinatus. Lift.

Concha Atriata echinata. Bonan.

Concha cordiformis, aequilatera, vmbone cardiorum vnito, ftriata papillofa, verrucofa aculeata vel imbricata. Lang. teft.

Gualt. teft. t.72. f. B.

Klein, oftr. t. Ió. f. 40.

Dan. Knudred Hierte - musling.

Groenl. Kirkfoaurfak.

Teita rufo fufea margine et medio fafciis abruptis albidis, fulcis profundis viginti ab vmbone ad marginem exarata ; coftae carinatae, carina aculeis obfoletis marginem verfus increfcentibus obfita; vmbones vero mutici funt. Margo valuularum ex fulcis et coftis vndatus, feu alternatim concauus et conuexus eft, ita tamen, vt alterius fulcus oppofitae coftae refpondeat, ac eidem in claufa tefta inferitur. Dentes cardinis medii duo in quavis valuula, approximati; laterales remotiores, poftici maiores.

Animal falciforme feu 'fi mauis pediforme; maffa enim principalis imaginem pedis non tantum offert, fed 
vfum quoque praeftat; pulchre miniata eft, carnofa et rotundata. Tibia et planta aequales, latere angulum efficiente fubfulcatae; planta tamen acuminata eft. Bafin cingunt plurimae lamellae Atriatae fufcae et aurantiae. Siphones breues vix vltra teftam porrecti cirris longis pendulis cinguntur. Membrana, interiora valcularum obueftiens, e flauo viridis eft, margo vero albidus maculis aurantiis tingitur.

Tab. I3. Fig. I. Cardium in quiete apertis valunlis porrectisque fiphonibus.

Fig. 2. Idem in inceffu.

Tab. I4. Fig. I. alteram valuularum cum iniacente animali, lamellas, membranas et cire ros fiphonum.

Fig. 2. Valuularum alteram cum fua membrana ac cirris adhaerentibus.

Fig. 3. et 4. Cardines valuularum dentatos exhibent: 
Tab. XV:

\section{ASCIDIA RVSTICA.}

ASCIDIA fcabra, ferruginea, aperturis incarnatis. Linn. Syft. p. 1087 . Zvol. d. prodr. 2720.

Tethya Rondel. pifc. 2, c. 19. fig.

Mentula marina informis. Flanc. conch. p. rog.

t. 7. f. A. D. E. F. Comm. Bonon. 5. p. 243.

t. 2. f. 4-7.

Dan. Bonde -Söe-pungen.

Liburn. Carnumi.

Ariminenf. Spongia.

Huius defcriptionem et figuram Celeb. Koenig Linnaeo primus ex Islandia obtulit, ego poftea plures varii voluminis in finubus Noruegiae reperi:

Mollufcum coriaceum, adulta aetate groflum, cylindraceum, lutefcens, aliquantum finuatum, vtraque extremitate obtufum, rugis transuerfis, tuberculisque fparfis obfitum; iuniori vero vel fubfphaericum vel globofum, glabrum vel fcabrum, rofeum vel rufo fufcum. obfoletae.

Aperturae binae ruberrimae, terminales, in adultis

Cutis extus fcabriufcula, intus laeuiffima et alba, feu, vti Plancus rem enunciat, veluti perlacea eft.

Sacculus (feu pulpamentum) ruberrimus bafin verfus flauefcit, laeuus ftriis frequentiffimis longitudinalibus, carnofus, mollis, ab omni parte liber, absque maffa ouali, qualis in A. Mentula aderat, vndique idem, folis collis in aperturis binis adeo haefit, vt vi retraherentur; haec apice aliquantum crenata funt. Intus concolor absque ftriis, corpufculis vero flauidis piriformibus, fparfis obfitus erat. 
Inteftinum latiufculum, nigrum, flexuris feptem vel octo, humo repletum, mediam longitudinem occupauerat; reticulum rubrum, cuius fibrae transuerfales longitudinaliter craffiores erant, inteftinum obuelaue. rant. Vafa pinguedinofa alba varii voluminis reliquum explebant.

Communionem inteftinorum vtraque apertura fruftra quaefiui; fpatium inter facculum et cutem exteriorem aqua refertum eft incifione enim profiluit, ac altera apertura pro lubitu animalis proiicitur.

Pulli diuerfae aetatis parenti faepe adhaerent, minores albi, maiores coccinei, puncta bina rubra loco aperturam praeferentes.

Hanc effe Spongiam Planci, cuius pulpamentum ab Italis editur, defcriptio et figurae $A$ et $D$ maxime fuadent; $\mathrm{D}$ et $\mathrm{E}$ vero monftrofae Afc. Mentulae Zool. Tab. 8. meliús conueniunt, radicesque feu pedes, quos Plancus indicat, a noftris aeque alieni.

Pulpamentum Afcidiae, quam fub nomine Alcyonii Phufcae defcripfit For Jkahlius anim. p. 129. huic fimile eft ac a Graecis crudum, fucco Limoniorum imbutum vefcitur.

In teftis Mytilorum, Balanorum et in fucis paffim, maiores tamen rarae funt.

Fig. I. binas Afcidias iuniores mammillares fuco adhaerentes, aperturasque incarnatas.

Fig. 2. Pulpamentum edule, feu facculum excifum.

Fig. 3. Afcidiam matrem Balano infidentem, pullosque maiores et minores Balano et ipfi matri affixos.

Fig. 4. Pulpamentum eiusdem bicorne.

Fig. 5. Pulpamentum feu facculum forcipe diuifum, vt inteftina et vafa pinguia appareant, exhibet. 
Tab. XVI.

\title{
PEDICELLARIA*) GLOBIFERA.
}

PEDICELLARIA capite fphaerico, collo nullo. Zool. d. prodr. 2782.

\author{
Dan. Kirfebaer-Stilken.
}

capitvicum pallide rubrum feu rofeum, globofum, vertice claufo vel fiffo. Collum prorfus nullum. $\boldsymbol{P}_{\text {edicellus capite fextuplo longior rufus, oculo armato }}$ membranula pellucida alba cinctus.

\section{In Echino Dröbachien/.}

Fig. I. et 2. Pedicellariam globiferam capite aperto et claufo naturali,

Fig. 3. et 4. eandem aucta,

Fig. 5. eandem valde ámplificata magnitudine monftrat

*) Inter aculeos Echinorum praefertim Dröbacbienfis et faxatilis animalia haec ignota fingularis figurae, nudo oculo vifibilia copiofe infident; alia tridentis Neptuni, et haec maioris moduli funt,' aliâ ceraforum pedicellatorum formam habent. Eodem loco femper affixa manent, nec alibi, quam in apice capituli motum quendam obferuaui, hoc aperiri et claudi, lobos et ariftas feiungi et rurfus apice vniri vidi. Pedicelli vel perpendicularem vel obliquum fitum habent forte ex folo aquae motu. 


\section{PEDICELLARIA TRIPHYLLA.}

PEDICELLARIA capite trilobo, lobis fubquadrangularibus muticis, collo tereti. Zool. d. prodr. 2781 .

\section{Dan. Klever - Stilken.}

совт maiores fubquadrati, hyalini, apice latiores, minores ouato acuminati, omnes mutici feu absque ariftis, fubrubentes.

colcvm teres, flexuofum, caerulefcens.

PEDiceltus collo fere breuior, rufus.

In Echino Dröbachien/.

Fig. 6. Pedicellariam triphyllam capite claufo et aperto naturali,

Fig. 7. et 8. eandem aueta,

Fig. 9. varietatem lobis quadratis valde auctam ex. hibet. 


\section{PEDICELLARIA TRIDENS.}

PEDICELLARIA capite trilobo, lobis oualibus ariftatis, collo tereti. Zool. d. prodr. 2780.

Dan. Trefork-Stilken.

conpvs fubrubrum pellucens.

zoni minini ouales tres, arifta longa ftricta terminali. corcvm elongatum teres, pellucidum, plerumque album, pedicello dupló vel triplo brevius.

ARIS TAE collo longiores apice patent vel vniuntur pro lubitu animalis; caput rarius quadrilobum, ariftis quatuor.

Variat absque ariftis, an perditis?

Hanc $\mathrm{Cl}$. Bafter pro probofcide tricufpidata animalis fumfit. Subfec. p. 139. Vol. r.

In Echino Dröbachienfi et faxatili copiofe infident.

Fig. 10. Tres Pedicellarias Tridentes aritis claufis et patentibus naturali magnitudine

Fig. I I. 12, easdem aukto volumine

Fig. I3.' जnicam claufis ariftis valde ampliatan

Fig. I4. quadridentem

Fig. I 5. quadrilobam nuticam offerts 
Tab. XVII.

\section{DORIS CLAVIGERA.}

DORIS oualis candida, pedicellis dorf clauatis croceis. Zool. d. prodr. 2770.
Dan. Köl- fingrede Doris.
Long. Io lin. lat. 3 lin.

Mirifice et perquam largiter Creator O.M. animalculum hoc exornauit.

CORPVS colore lactis caeruleo album, pellucidum; oblongum, antice dilatatum, obtufum, poftice extenfum, acuminatum; dorfum punctis conuexis croceis diuerfae magnitudinis afperfum, margoque totus (caudae extremitate excepta) obfitus pedicellis albis, capite croceo granulato inftruetis, nouem nempe in quouis margine laterali, quatuorque in antice minoribus; horum quatuor minores diuergentes vltra medium dorfi poftica verfus confpiciuntur, an locum ani decorantes, quod analogia quidem iubet, foraminulum vero ne microfcopio quidem detegere potui; apex caudae itidem croceus eft. Pedicelli Clauarias militares croceas mentiuntur.

TENTACvla duo in anteriore dorfi, acuminata, tota crocea, haec retraßtilia funt; clauae marginales ad latus flexiles funt, dorfales corripi et produci videntur; non enim femper aeque vifibiles, exiftunt.

Subtus plana, tota alba; medio inteftinum obfcurum pellucet.

CapvT vt in Limacibus a pede diferetum, oris in medio veftigium. Ab vtroque capitis latere papilla cro. cea, apice truncata, fubemarginata confoicitur.
C 2
Quoties 
Quoties margo lateralis dorfi aliquantum eleuatur, feries punctorum croceorum infra eundem in confpectum fubeunt.

Supina in fummo aquae quiefcere amat, vnde forśKAHLI vS congenerem tergipedem vocauit, at hoc Doribus plurimisque Cochleis marinis et fuuiatilibus commune eft. Limaces eius (Animal. defcript. p. 99.) generi Doris adfcribi debeit, et quidem marina noftra Doris fafciculata Zool. d. pr. 2.772, tergipes lacinulata, 1.c. 2779, et minima papillofa 2775 , feu Limax papillofus L IN NAE I eft.

In Fucis finum Norvegiae pafin.

Fig. I. naturali magnirudine

Fig. 2. yronam et

Fig. 3. fupinam aucta magnitudine fiftit. 


\section{DORIS QVADRILINEATA.}

DORIS oblonga, alba, lineis quatuor nigris, auriculis fulphureis. Zool. d. prodr. 2771 .

Dan. Fire - ftregede Doris.

Long. 4 lin. lat. $I \frac{x}{2}$ lin.

Animalculum viuar.

Corpus oblongum, extenfum, album, antice obtufum, poftice acuminatum, dorfo conuexum, lineis quatuor longitudinalibus interruptis nigris, duabus nempe in ipfa dorfi carina, reliquis in margine, maculisque fulphureis infcriptum. inftruitur.

Frons auriculis feu mucronibus quatuor fulphureis

In antica dorfi parte Tentacula bina, diftantia, brevia, obtufa, albida, margine crenulato, nigro; in poftica trina alia corpufcula approximata tentacula magnitudine et forma aequantia, pone haec protuberantiae duae maiores, cylindricae, albae, apice fulphureae.

'Subtus planum, album, in medio macula inteftini fubrubens pellucet; in hac pagina caput a corpore rimula difcretum videtur, interftitiumque vtrinque puncto fulphureo notatum.

Os confpicuum.

In Fucis finus Dröbachienfis haud infrequens.

Fig. 4. magnitudine naturali

Fig. 5. pronam, et

Fig. 6. fupinam ampliatam exhibet. 
Tab. XVIII.

\section{NEREIS TVBICOLA.}

Nereis fubdepreffa, pedibus fubcirratis globolis. Zool. d. pr. 2625 .

Dan. Rör-Nereiden.

corpys lineare luteum, fupra conuexum, fubtus planiufculum, articulatum. Articulús feu fegmentum quoduis vtrinque inftruitur verrucula globulari, fafciculo fetarum in Nereidibus folito filamentis binis breuiffmis (vix enim dimidia corporis latitudine longiora funt) interpofito; in prioribus fegmentis filamenta a quouis latere quatuor confpicere videbar. Segmenta 94 , primum absque verruca globulari, reliqua aequalia (poftica tamen minora) pedibus inftructa numeraui. Collum anguftum et muticum. Linea rubra dorfum totius corporis percurrit.

Caput antice tentaculis quinque, tribus nempe longis (longitudinem feptem fegmentorum adaequant) binisque lateralibus triplo breuioribus, omnibus bafi articulatis, fupra punctis binis nigris, feu oculis, fubtus papillis quatuor fphaericis, oreque in medio inftruitur. terminatur.

Cauda filamentis duobus porrectis, raro quatuor

Singularis in hac eft tubulus, quem inhabitat, ipfaque non ex heterogeneis compilatis, fed ex proprio fucco fabricat; membrana enim fubtilis, lenta, pellucidisfima, glaberrima eft, vitrumque recens adeo refert, vt tubum capillarem diceres; adeoque fegmentum quoduis corporis numerare, totumque vermem intra tubulum latitantem perfpicere permittit. 
Nereidum in vagas et tubulicolas, quarum hae Tere. dinem lapidariam, Sabellam granulatam, frrupofam et Chryfodontem meas Amphitrites, continerent, illae Nereides et Naides, diuifonem infringit iam delcripta Tubicola, vagis in omnibus fimilis, tubo folo excepto.

Extra argillam etiamfi in vafculo aqua marina ple. no pofita effet, tubulo fenfim retrorfum exiit languida et moribunda; alia enim profundi maris, alia humoris in vafculo temperatura eft.

In argillofo fedimento finus Dröbach profunditate octoginta orgyarum decem, omnes eiusdem voluminis, extraxi.

Fig. I. Vermem in tubulo,

Fig. 2. extra tubulum

Fig. 3. tubulumque vacuum magnitudine naturali ex: hibet.

Fig. 4. caput et collum fuperne

Fig. 5. idem cum primo corporis fegmento inferne,

Fig. 6. fectionem duorum fegmentorum cum cirris, fafciculo fetarum et verruca globulari aueta magnitudine fittit. 


\section{Tab. XIX.}

\section{ASTERIAS PVLVILLVS.}

ASTERIAS lunata lubrica, margine integro mutilo. Zoul. d. prodr. 2827.

Dan. Tabouret-Stiernen; Naale-puden.

Inter pulchriores Afterias haec locum obtinet.

Dorfum feu fuperficies tota nigro - rubra feu fanguinea, punftis cufpidalibus miliariis albis in ftrigas decem a centro ad apicem absque ordine fparfis; haec puncta funt cufpides carnofae, lubricae et muticae. In ipfa cruenta cute frriae quaedam transuerfae minores et pallidiores ad marginem excurrentes. Margo vix articulatus, cufpidibus decem et vltra, angulum, quem cornua fiue radii efficiunt, occupantibus. Subtus alba, glabra, vmbra rofacea intra marginem: Sulci quinque pinnulis horizontalibus tecti; area intercepta areolis inaequalibus quafi teffellata eft.

Corpus noftratibus reliquis craffus, puluinatum, feu fuperne valde conuexum, fubtus cauum, apicibus cornuum quafi totidem pedibus fuffultum; radios enim extendere, nec tentacula exferere mihi vnquam, dies licet apud me vitam produxerit, vifa eit. Exficcata fupra fcabra euafit, margoque fubarticulatus apparuit; fubtus variolofa eft.

Proxime accedit Afteriae pifince, quam viuam haud vidi. Maeandrites in hac vti in congeneribus.

Aqua ferwente perfufa ipfam aquam colore rubicundo tinxit; puncta cufpidalia alba in feruida aqua euanefcunt, feu in puncta fuccinea coagulantur.

In finu Dröbachienfi iuxta infulam Kaholm reperi 1773 rarifimam.

Fig. I. Afterianı naturali fitu,

Fig. 2. paginam inferiorem radii monftrat. 
Tab. XX.

\section{CALLIONYMVS DRACVNCVLVS.}

CALLIONYMVS, pinnae dorfalis prioris radiis corpore breuioribus. Linn. Syft. p. 434 .Zonl. d. pr. 338 .

Draco minor araneus. Rond. Ionft. t. 2 r. f. 3 .

Cottus pinna fecunda dorfi alba. Arted. gen. p. 49. Syn. p. 77.

Caryftion pinnis longiffmis, partim aurei, partim argentei coloris, ventre lato plano candido. Klein. piic. mif. 4. P. 47. n. Io.

Vranofcopus officulo primo pinnae dorfalis primae vnciali. Gron. Muf. ז. n. 6.3 . Zooph. n. 204. Ad. Helv. 4. p. 260. n. 125.

Dracunculus. Worm. Muf. p. 268.

Norv. Faefing.

Germ. Kleiner Meer-Drache.

Belg. Schelvis-Duyvel.

Radii dorf. 4, 10.Peहt. I 5. Vent. 6. An. ro. Caud. 7. Dorf. 4, I0. P. 18 . V. 5. A. Io. C. 10.

corpvs fubdepreffum, fupra cinereum maculis rubentibus, fubtus album, vbique immaculatum.

maxilla fuperior longior eft.

SPINA triplex in operculis.

PINNAE dorfalis anterioris radius primus longitudine radiorum in prima dorfali poftica, reliqui decrefcendo minores, quartus in quibusdam remotus; ipfa pinna ramentacea et fingularis nigra: pinna dorfalis poftica radiis fubaequalibus, lineis longitudinalibus tribus ex maculis fufcis.

C 5 svecvs 
SvLCVs in dorfo minus profundus, quam in C. IxRA. Vtraque dorfi pinna in fulco conditur, raro explicatur.

Pinna pectoralis tenuis et pellucidiffima.

Radii in pinna ventrali ramofi, coftaeque validae. les albi.

crRRVs minimus ante anum; radii anales aequa-

FORAMINA aquam refpirantia duo paria, anteriora in angulo operculorum dorfali, pofteriora vtrinque fub initium pinnae dorfalis anterioris; aqua ex omnibus quovis halitu, aequali interuallo fimul ope branchiarum prafilit, atque in dorfo vnitur.

Variat fupra cinereo luteus, maculis in capite et antica dorfi, fafciisque binis in poftica nigricantibus.

Cui locum natalem Genuam et Romam fecere auEores, in finu Norvegiae Dröbachienf frequens reperitur pifcis.

Wormii pifcis circa promontorium Scaven in Cimbria captus eft; defcriptio conuenit, pinnis dorfalibus exceptis, quarum prima aureis et argenteis lineis diftincta, pofterior vero magna admodum dicitur.

Fig. 1. Dracunculum naturali magnitudine exhibet. 
Tab. XXI.

\title{
HIRVDO GROSSA.
}

HIRVDO dilatata flauicans, antice fiffa. Zool. $\mathrm{d}$, prodr. 2668.

\author{
Dan. Tyk-igle. \\ Long. I 2. lat. 7. lin.
}

corpys groffum, flauo cinereum, lineolis albis in figuram fquamularum obfitum, antice acuminatum, flavum, apice obtufo fiffum. Fiffura feu foramen punctis pertufum ope lenticulae apparet, ac pro ore inferuit; hoc apertum et microfcopio vifum papillis contiguis fcabrum confpicitur. Totum fere corpus, collum fi excipias, ouis, quae ex ore cum materia gelatinofa millena euomit, refertum eft.

Ipfa ova fphaerica, ope microfcopii fauicantia, fubpellucida, lunulam opacam produnt, quae embryo eft, ac quaeuis materia maxime hyalina, nec ab ipfa aqua diftinguenda cinguntur.

BA sis fiue poftica pars in orbiculum flauum dilatata, quo obiectis firmiter adhaeret; fupra orbiculum in ipfo corpore papilla flauicans, quae interdum in foramen aperitur, anumque prodere videtur.

Ab ore in dorfo extenditur IN TESTIN vM flatum, medio dorfo in varios anfractus aequales diductum. VENTER dorfo concolor, inteftinis flauis magis flexuofis nec ad os pertingentibus.

Partem anteriorem ore aperto lente in vtrumqua latus mouet, efcam forte quaeritans. 
Ex ano quoque materiem mucidann excernere vidi.

In agone mortis inteftinum conuolutum ex poro in dextra ventris parte protrufit.

In VENERE EXoLETA iuxta cardinem intra branchias fruftum carnofum animalis mentitur.

Fig. I. Hirudinem a tergo,

Fig. 2. eandem a ventre naturali magnitudine fiftit.

Fig. 3. Anticam hirudinis rictumque fcabrum ac partein ouarii aucta magnitudine,

Fig. 4. congeriem ouulorum in gelatina naturali,

Fig. 5. aucta magnitudine exhibet. 


\section{Táb. XXII. \\ LVMBRICVS FRAGILIS.}

LVMBRICVS ruber, verrucis lateralibus fiffis, fetis fafciculatis. Zool. d. prodr. 261 I.

Dan. Skiör - ormen.

Facies ominino Lumbrici terreftris, at annuli diftinctiores fragilesque, prorfus vti in Iulo terreftri, vltra 200; bini capiti proximi absque pedibus, horumque folo defectu pars nofcitur antica; altera enim, quae ergo poftica et abrupta videbatur, mihi dehinc minus innotuit.

Iedes fimplices; fafciculo enim fetarum rariorum, fubiacenteque papilla carnea fetis breuiore, fiffa, componuntur.

CAPvT conftat ligula conuexa, fubtus concaua; infra hanc fubtus os rugulofum, palpique bini paruuli, carnei.

In argillofis finus Dröbachienfis raro.

Fig. I. Lumbricum fragilem naturali magnitudine,

Fig. 2. fex antica fegmenta cum capire fuperne vifa,

Fig. 3. partem inferiorem capitis cum oré et collo auctà magnitudine fiftit. 


\section{LVMBRICVS ARMIGER.}

LVMBRICVS ruber, lamellis ventris lanceolatis, geminatis, antice nullis. Zool. d. prodr. 2610.

Long. 20 lin. lat. $\frac{x}{2}$ lin.

Corpus teres, rufum, fegmentis vltra centum compofitum; horum 17 priora mutica, fubtus punßtis vtrinque binis nigricantibus, altero maiore notantur; reliqua tumida feu vtrinque in coftam albidam eleuata; haec ventrem verfus vtrinque prominet ac verrucula fiffa terminatur; huic adiacet feta fimplex, breuis, tenerrima, aegre lenti confpicua. Segmenta bina muticis proxima folis verrucis, reliqua coftatorum praeter verrucas lamellis lanceolatis acutis a quouis latere armantur. Totum corpus in dorfo percurrit linea rubra, aliaque itidem in ventre, quas venam et arteriam diceres.

In lima finus Teifholm. Chriftianfandenf. rarus.

Fig. 4. Lumbricum armigerum naturali,

Fig. 5. partem Lumbrici anticam anka magnitudine filtit. 
Tab. XXIII.

\section{ACTINIA RVFA.}

ACTINIA rugofa, foramine rofaceo, cirris pallidis. Zool. d. pr. 2797.

Priapus fenilis fubcylindricus rugofus. Linn. Fn. fu. 2103 .

A tinia fubcylindrica transuerfe rugofa. Lim Syft. p. 108 .

Act. angl. Vol.63.t. I6. f. 1, 2, 3.

Gall. Cul d'afne; Cubafieau.

Vti congeneres varias induit formas, quasdam in: dicare libet: vel cylindrica eft et farta, diametro trans. verfali et perpendiculari fere aequali, in circulos quinque vel fex convexos deprefia, et quafi pedibus quinque membranaceis proftantibus fuffulta; centro apicis in hoc ftatu tentacula omnia adeo collata funt,' vt apices paucorum tantum videantur; piures horas ita perfiftit.

Mortua pallida euadit, ftrisque minutiffmis longitudinalibus notatur.

Vel tota fphaerica eft et infata, vel pars fuperior fphaerica, inferior rugofa, tentaculis retractis verticemque apertum occupartibus; tum friae fubtilifimae circulares et longitudinales pellucent, ac bafis in vtroque ftatu dilatata vndatimque eleuata et depreffa eit. Vel plenarie euoluta, ac tum pars antica dilatata albida, difco glabro, centro aperto, corpufculis oualibus in figuram rofaceam cincto, margineque tentaculis confertis cingitur; haec fliformia, albida, truncata, diametro difci breviora funt, et pro lubitu vermis fingulatim vel fimul mouentur، 
Huc referenda videtur Vrtica marina libera ARISTOTELIS et RONDELETII hiftoire des poiff. 380 . f.

Poffit effe ACt. Senilis LINNA EI, fi defcriptionem fpecificam refpicis, fi fynonyma minime; BASTERI enim fig. 2. t. I 3. AEt. plumofam Zool. d. prodr. 279 r. valde diuerfam offert, et fig. 2. t. 14 . minus bene A. Senili fub. ftituitur, cun ftrias longitudinales habeat; nec sтröMII Söndmör. p. 204. quae mea Crafjicornis eft. Zool. d. pr. 2792. Figurae E et F. t. 9. planc. conch. app. quodammodo A. rufae conueniunt; defcriptio vero nimis ofcitanter facta eft. Fig. I, 2, 3. t. I 6. Clariff. діскемA$\mathbf{R E}$ in $\sigma_{3} \mathrm{vol}$. Act. angl., quae rufam offerunt, illuftris SOLANDER quidem equinam LiNNAEI dicit, at huius fpecifica defcriptio, Jemioualis laeuiufcula, nimis vaga eft, ac reliquis aeque competit.

Figurae $\mathrm{F}$ et $\mathrm{G}$ t. 27 FORSKAHLTI animal. defcr., quarum nullibi meminit ipfe auctor, ad Actinias potius, quam ad Madreporas referendae funt; Fig. F plura cum mea A.t. coccinea Zool. d. pr. 2794. communia habet.

In fcopulis portus Laurvigenfis.

Fig. I. Aciniam rufam, glabram et fphaericam tentacuculis retractis,

Fig. 2. eandem rugofam,

Fig. 3. rugofam et repandam tentaculis patulis,

Fig. 4. ex parte fphaericam et glabram, ex parte rugofam tentaculis conditis,

Fig. 5. eandem rugofam et conicam exhibet.

Tab. 
Tab. XXIV.

\section{PATELLA FVLVA.}

PATELLA tefta integerrima aurantia, vertice mucronato, fubmarginali. Zoul. d. prodr. 2869.

Dan. Röd-guule Patelle.

TESTA glabra immaculata fulua, oculo armato 2 vertice ad marginem fubtiliter conuexe ftriata, ftriis fubtilioribus, concentricis, impreffis. Vncus verticis a centro remotus eft.

Limax albus capite orbiculari, inferne vtrinque hamulo infructo, fuperne tentaculis filiformilus binis extra teftam aliquantum porrectis. Pes oblongus; $\mathrm{Pal}$ lium albidum margine integro, dextra in lacinias duas lanceolatas interdum plicatur.

In finu Dröbaclicingl haud frequens.

Fig. I. Teftam naturali magnitudine fuperne vilam,

Fig. 2. eandem et

Fig. 3. aperturam cum inhaerente hof pite aucta magnitudine exhibet. 


\section{PATELLA FISSVRELLA.}

PATELLA tefta fulcata, vertice recuruo, antice perfurato. Zool. d. prodr. 2865 .

Dan. Rift-Patellen.

Facies $P$ at. Fiffurae, quam facile crederes, at minor, nec reticulata eft, nec incifura vlla, quae in illa a margine ad mediam fere teftae altitudinem fplendida eft, fed foramine non in ipfo vertice, fed antice infra eun. dem infignitur; adde, quod iuniores Fiffurae magnitudine Fiffurellae inuenerim, diftinctam incifuram marginis habentes; quid, quod foramen in fria lata, non in fulco factum.

\section{In fucis Dröbachienfibus raro.}

Fig. 4. Fiffurellam naturali,

Fig. 5. aucta magnitudine, et

Fig. 6. aperturam teftae ampliatam exhibet. 


\section{PATELLA FISSVRA.}

PATELLA tefta fulcato-reticulata; vertice recuruo, margine antice furfum fiffo. Zool. d. pr. 2864. Patella tefta ouali, ftriato - reticulata, vertice recuruo,antice fiffa. Linn. Syft. I 26 I. Act. Nidrof. 4. p. 371, 100 .

Patella cornuta minor. Ginann. op. vol. I. P 4. t. 3. f. 25 . male.

Patella reticulata exigua alba, fiffura notabili in margine. Klein. oftr. p. $1 \mathbf{1} 6$.

Lift. conch. t. 543 . f. 28 .

Petiv. gaz. t. 75 : f. 2.

Dan. Split-patellen.

TEST A extus cinerea a vertice ad marginem fulcata; margines fulcorum nodulofi funt; interftitia vero Atriis eleuatis transuerfim notantur, vel ftriae fulcorum granulatae funt, ipfique fulci punctis excauatis duplicibus impreffi, hinc tefta reticulata confpicitur. VERTEX aduncus, non perforatus, vti in Linnaeana. Tefta intus alba, glabra, margine ferrato. FISSvRA in parte antica linearis a margine vltra tertiam altitudinis partem, et quidem in fulco eft, non in ftria conuexa, proque incremento teftae deorfum clauditur.

LIMAX albus, tentaculis binis fetaceis; oculis extus ad bafin. Pallium cinereo-obfcurum, margine finuato albo.

CAPVT in hac, quod fingulare, fiffurae adiacet, h. e. parti teftae a mucrone remotiori.

In fundo finus Dröbachienfis fupra faxa, ac in coralliis maris Norvegiae haud vulgaris.

Fig. 7. Fiffuram naturali,

Fig. 8. eandem, et

Fig. 9. aperturam teftae cum inhaerente Limace aucta magnitudine exhibet. 


\section{Tab. XXV. ASCIDIA VENOSA.}

ASCiDIA elongata, fubcomprefla, rubra, facculo concolore. Zool. d. prodr. 2736 .

Dan. Röd-aared Söe-pung.

Animal totum rubrum feu fanguineum; cutis exterior gelațino - cartilaginea, pellucida, alba, ramificationibus fubtiliffimis fanguineis inlcripta. cor.tvm feu fuperior pars inteftini flaccidum, pulchre fanguineum, ope lentis ramificationibus confípicuis. APERT VRA altera in fummitate, altera infra medium remota, vtraque apice papillis 6 violaceis terminata: fi membrana haec caute auferatur, in confpectum fubit alia membrana, interanea animalis ab hoc latere cooperiens; interior pagina prioris membranae, ac exterior fecundae ftriis pun chre reticulata eft; vtraque pallide rubens, punctis raris fanguineis faepe infcripta, aream vacuam, quae forte aqua in viuis repletur; continet; $\mathrm{ab}$ altero corporis latere membrana haec duplicata prorius deeft. PAPILLAE violaceae in quibusdam minus confpicuae. JN TES TrNVM liberum folis apicibus aperturarum ac ligamento tenui cuti adhaeret. DVODEN VM, groffum, nigricans, flexuofum, ad aperturam inferiorem pertingit; infra hóc aliud inteftinum curuatum album, an ouarium? vtrumque multa pinguedine inuolutum, cui immixta fafcia fubftantiae flauae, an bilis?

Defcriptio Afcidiae gelatino fae вона dsсн mar. $\mathbf{3} \mathbf{r}$. t. 10. f. 3. huic conuenit, at figura minus.

Figura Alcyonii Phufca forskantit Tab. 27, D, quod fpecies Afcidiae ef, quidem in noftrain quadrat, at in defcriptione cortex fupofus et huic et gelatinofae nimis repugnat; Fig. E tab. 27, minime eft Ajcidic qua- 
dridentata, vti voluit chartarum pofthumarum ForsKAHLII ordinator anonymus, ab editore, qui nec Latinam linguam nec hiftoriam naturalem callet, diuerfus, fed ipfa Phufca Forsicaniri.

Frequens circa vrbem Chriftianfand.

Intra cutem huius MYis ILvs difcors, fimili modo vti in cute ascidia Mentulae, bene latet et viuit.

Fig. I. quatuor Afcidias fuco rubro infidentes naturali,

Fig. 2. partem cutis exterioris venofae,

Fig. 3. partem interioris reticulatae ftriis variis pulchre rubris aucta magnitudine monftrat. 


\section{Tab. XXVI. \\ AMPHITRITE AVRICOMA.}

AMPHITRITE cirris binis vtrinque, antice flabellis duobus aureis rigidis. Zool. d. prodr. 2622 .

Sabella granulata tefta folitaria libera fimplici curuata: granis arenaceis fufcis. Linn. Syft. p. 1268.

Dan. Guld-Kammen.

Groenl. Imab - polik.

Tubulum primus reperit in mari Islandico expes rientiffimus KOENIG, LINNAEOque mifit, qui eum ob fubftantiam arenulofam generi Sabellae fubftituit, iure quidem, fi ad tubulum tantum refpicis, at tum Sabella Penicillus, qui omni arenula deftituitur, remouenda effet; Nereis cirrofa, tubulum quidem arenulis permixtum habens, locum huius occuparet; fi vero ad animal, aliud genus pofcit, cum nec Nereis fit, nec os ringens habeat, Sabellaque ringens, hofpite diuerfiffimo inftructa, aeque feponenda erit, vt taceam, totum genus ordini teftaceorum minus bene accenferi. Mirus fatis animalium diverforum generum confluxus ad nouum Sabellae genus conftituendum, inque maiorem confufionem, quae, quamdiu charąteres generici ex domicilio animalis petuntur, nunquam euitantur; disiungi rurfus ac fuum cuique reddi animalium fabrica vrgebat. Ob tentacula flexuofa et pendula, corporis fimilem ftructuram, ac tubum fragilem generi Amphitritis hunc vermem adpofui; plures quidem viuas examini fubieci, at exactiffima Clar. pAt-as hiftoria et defcriptio Nereidis Belgicae, quae improprie Nereis audit, quod quidem acutiffimus auctor Mifcell. I I 4 praeuidit, vlteriorem. A. auricomae dare vetat, differentiam indiçare fufficit, reliqua vti in Belgica azL. Mife. p. II7, t. 9. f. I-1x vifa funt. 
Tvвvs, quo continetur, curuatus, et teruncialis cum femiffe eft, fragilis, pellucidus, alteramque extremitatem verfus attenuatus, intus laeuis, extus ex arenulis folitariis fibi in glutine exfudato adpofitis confertus.

cORPvS pellucidum, fupra et infra laeuiffimum, nitidum absque rugis aut fegmentorum interfectione. INTESTINVM longitudinaliter pellucet.

Palmvea quaeuis conftat paleolis auro fplendentibus, quatuor interioribus minoribus, nouem exterioribus extrorfum decrefcentibus; area concaua pone palmulas in noftra rugofa feu curuatim ftriata eft, marginem ferratum habet. natur.

Appendix fcaphoidea vti in Capenfi Ligula termi-

Ad orientem infulae Haä̈en finus Chriftianen/is, ac ad fcopulos Teiftholmen Chriftianfandenfes copiofe.

Fig. I. Auricomam e tubo extractam et fupinam,

Fig. 3. pronam,

Fig. 2. vero tubulo inhaerentem, capite excepto, femper extra tubum proftante, confpiciendam praebet.

Fig. 4. Partem colli fupinam cum binis branchiis vtrin* que, capitis cum tentaculis pendulis, cirris lateralibus limbun cirratum et palmulas aureas;

Fig. 5. partem tubi pronam ac caput protenfum cumpalmulis, parte rugofa, margine ferrato et cirro laterali;

Fig. 6. vero appendicem fcaphoideam fuperne vifam auła magnitudine exhibet.

$$
D_{4} \text { Tab. }
$$


Tab. XXVII.

\section{CALLIONYMVS LYRA.}

CALLIONYMVS, pinnae dorfalis prioris radiis longitudine corporis. Linn. Syft. p. 433. Zool. d. prodr. 337.

Lyra haruicenfis, pinna dorfali longiffima, maculis coerulefcentibus. Petiv. gaz. t. 22. f. 2.

Trachinus maxilla fuperiote longiore, pinna dorfi priore altiffima. Linn. Fn. fu. 1283 .

Cucullus leuis coeruleo - flauefcens, cui in fupremo capite branchiarum opercula. ACr. ang!. 1749. n. 293. f. I.

Vranofcopus officulo primo pinnae dorfalis longitudine corporis. Gron. Muf. 1. p. 23.64 . Zooph. p. 57. 206. A\&t. helv. 4. p. 260 :

Cottus officulis pinnae dorfalis longitudine corporis. Gron. Act. Vpf. 1740. p. I 2 I.t. 8.

Exocoeti tertium genus Bellonio. Seb. thel. $3 \cdot \mathrm{p}$. 92,7 . t. $30, \mathrm{f} .7$.

Caryftion officulo pinnae dorfali, primo longifimo. Klein. add. mif. 4 . p. 93 .

Dracunculus marinus. Borl. Cornub. t. 26, f. Io, 1 I . Ström. Söndm. I. p. 278. Valent. mul. mufeor. 2, p. 164, t. $32, f .7$.

Dracunculus Rondeletii. Willugb. hift. pifc.p. 136 . t. H. 6. f. 3. mala.

Dracunculus aranei fpecies. Ionft. pifc. t. 2 I.f.4. mala. Pont. N. N. 2. p. 1 80. f. mala.

Argenville Oryctologie. p. 535 .t.26. f.B.

Norv. Fafing; Floy-fifk.

Angl. The yellow Gurnard.

Germ. Englifche Leyer.

Byzant. Glini.

Totius long. $10 \frac{x}{2}$ vnc. Pin. dorf. prioris long. 5 vnc. pofterioris rad. 3 vnc.

Dorf.5, 10. Ped. 20. Vent. 5. A. Io. Caud. ro. 
pinifar et corpus pallide luteum, maculis et lineis coeruleis notatum; Pinnae dorfalis prioris radii duo anteriores longitudine trunci. CIRR vs breuis ante anum. Capitis latera poftice fpina triplici.

Clariff. Strömii defcriptio accurata. Nofter differt fpina triplici laterali, non quintuplici. Radii quatuor in membrana branchioftega in noftro confpicui funt. Pinnae dorf in noftro vix fulco infertae. Radii pinnae dorfalis prioris duo anteriores aequales funt, membranulaque exferti pungunt. Radii pinnae dorfalis pofterioris primi octo aequales vix longitudine tertii radii pinnae prioris, nonus et decimus longiores, pungentes.

Narratio Epifcopi Bergenfis de volatu huius pifcis fabulofa nimis, figuraque auriculis catelli, pinna pyramidali, roftroque auis, nimis rudis eft.

Licet figura et defcriptio apud willugreivm exfantes in paucis inter fe et a noftro difcrepent, eundem tamen pifcem effe nullus dubito.

Corpus fubtus album, coerulefcens, caput fubtus, pinnaeque ventrales et anales, margine atomis fparfis nigris. Radii pinnae analis bini pofteriores reliquis longiores funt.

Variat pinnae dorfalis prioris radiis quatuor, fecundo primo breuiore, pectoralis nouemdecim lineis coeruleis in pinna dorfali priore oblique transuerfalibus, radiis pinnae dorfalis pofterioris omnibus aequalibus, vltimis non pungentibus. In capite nec fulci, nec eleuationes offeae, quales in Strömii. Radii quatuor in membrana branchioftega. Pinnae, dorfales in fulco longitudinali.

Véfcitur Echino faxatili, Afteria ophiura et Squillis, has enim in inteftinis reperi.

In finú Dröbachienfi.

Lyram naturali magnitudine et fitu confpiciendarn praebet. 
Tab. XXVIII.

\section{VENVS ISLANDICA.}

VENVS tefta cordata, transuerfim ftriata rudi, nymphis hiantibus, ano nullo. Linn. Syft. p. I $13 \mathbf{I}$. Zool. d. prodr. 2977.

Concha ventricofa, craffa, laeuis, non aurita. Isl. Reif. I. D. 577 et 239.

Concha ventricofa biualuis, non ftriata, nec auriculata. Isl. Reif. I. D. 98. t. I I. f/8.

Norv. Rund-fkiael. Koe - $\mathrm{fkiael}$.

Isl. Ku-fkiael, Krok- fifkur.

Groenl. Epikfaunak.

Tefta cordata vernice quafi obducta: Valuulae extus fufcae, fcabriufculae, transuerfim cingulis cinctae, ftriisque transuerfis nitentibus, antice fubmembranaceis, quafi fetis equinis fubtiliffimis vndique fuperinductae. Intus albae absque nitore. Nates decorticatae. Dentes cardinis, medii acuti, tres in dextra, duo in finiftra valuu12; lateralis in antica parte duplex elongatus, diuergens, in poftica vix vllus. Margo integerrimus. Impreffio analis nulla.

Islandis edulis eft, paffim quoque in Islandica fofflis reperitur.

In finubus Noruegiae, Iślandiae et Groenlandiae.

Animal teftam inhabitans fingulariffimum; maffa nempe carnofa, rhomboidalis, aurantia, lamellaeque binae ftriatae, altera minor; vtrinque a bafi. feu a cardine teftae ad medium mafiae incumbentes. Membrana totas valvulas introrfum obueftiens, aliquantum retractilis pallida eft, marginemque aurantium integrum habet.

Sipho- 
Siphones bini in viuo animali apertis valuulis vix vltra marginem anticum porrecti; remotior a cardine maior eft; vterque cirris breuiffimis cingitur; rima quoque a latere fiphonum exteriore producta, cirrata eft.

Tefta in viuo quoque vix vltra duas aut tres lineas absque ruptione ligamenti cardinis aperitur.

Ad magnitudinem ouo gallinaceo quadruplo maio. rem excrefcit.

Fig. I. Concham naturali magnitudine eiusque fitum fiphonibus apertis,

Fig. 2. Totum animal, altera valuularum remota, maffam nempe carnofam, laminas ftriatas, membranam et fiphones cirratos aliquantum retractos ac veftigia binorum mufculorum, quorum ope animal valuulis affixum eft,

Fig. 3. Alteram laminam ftriatam ampliatam exhibet.

Fig. 4. Cardinem valuulae finiftrae,

Fig.5. Cardinem dextrae offert. 
Tab. XXIX.

\section{NEREIS PENNATA.}

NEREIS conuexa fegmento primo cornifero, tentaculis continuis, branchiis pennatis. Zool. d. pr. 2630.

Nereis Noruegica, glabra, fegmentis CXX annulari-

$\therefore$ bus, ore dentato, dupliciter forcipato. Linn. Syft. p. 1086.

Nereis Madreporae pertufae fegmentis CXX annularibus, ore dentato et dupliciter forcipato. AEt. Nidr. 4. p. SI. t. 2. f. 7-I 2.

IMuf. Kircher. claff. I 2. p.41 2. f. 8, 9, Io.

Dan. Fiær-Nereiden.

NEREIDI fequenti in plurimis conuenit, at fubtus planiufcula eft, fegmentaque minus diftincta.

corpvs elongatum, fubluteum, linea dorfi longitudinali rufa, fegmentis pediferis 126 compofitum. Quodlibet a 7 ad 40 vtrinque branchiis pennatis, feu rachide ab altero latere radios $6-1$ I emittente, anteriora nempe paucioribus fupra pedes, inftruitur.

pES quilibet conftat cirro fuperiore et verruca inferiore, in quorum medio proftant fetae. ticulata.

TENTACVLA vti in congeneribus integra, non ar-

os forcipatum pluribus adeo commune eft, vt exinde fubdiuifio in forcipatas et proboficieas in prodromo enata fit. Structura forcipis defcripta exftat ACt. Nidr. 4. p. 48. et von Würm. p. 122.

COLLVM et CORNICVLA vti in fequente.

CAVDA filamentis duobus longis terminatur.

Plurima huius indiuidua maximam corporis partem ab ytroque inteftini latere, fupra et fubtus globulis luteis 
pellucentibus referta erant; hos in nulla N. pinnata, diverfo licet tempore in plures inquifuerim, vnquam vidi, an ouula? an dehinc fexus fequior fequentis fit?

Hanc fpeciem Bonanni primus aere expreffit, GVNNER VS, cui hiftoria Noruegiae naturalis tantum debet, primus defcripfit, ac nomine Madreporae, in qua communiter reperitur, nuncupauit.

LIN NAEvs vero Noruegicam nomine triuiali dixit, at inter octodecim Nereidis fpecies, quas in prodromo recenfui, vndecim in Noruegiae finubus reperi.

GVNNERvs fuam in Madrepora et lacunis eius reperit, ego ibidem meam faepenumero, at ille quoque in tubulo papyraceo inuenit; tales tubulos ramis coralliorum affixos faepe quoque reperi, at femper vacuos; a Nereide vero confectos femper dubitaui, partim quia altera extremitate claufi erant, partim quia omnes huius fpecies a me vifae ne tubuli veftigium quidem haberent. Situs quoque vermis in fig. $\sigma$. AEt. Nidr. capite extremo claufo obuerfo abunde probat, tubulum non effe vermis proprium, fed alienum, quem pro tempore occupauerat; veros dehinc Nereides tubulos fibi fruentes rariffimae funt, inter plures enim vnicam modo fpeciem, quam

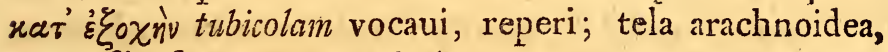
quam fibi finxit N. diuerficolor, von würm. P. I34, nomine tubuli minime falutari poteft.

In argillofis et in Madrepora pertufa finus Chriftiánienfis iuxta Stor-Skiaeren cum fequente.

Fig. I. Nereidem pennatam naturali,

Fig.2. Caput cum collu, oculis, tentaculis et labio bilobo,

Fig, 3. Segmentum corporis ouulis fartum, branchias pennatas, cirrosque pediformes ancta magnitudine' exhibet.

Tab. 
Tab. XXIX.

\section{NEREIS PINNATA.}

NEREIS conuexa, fegmento primo cornifero, tentaculis articulatis, branchiis pinnatis. Zool. d. pr. 2629.

Dan. Pind-Nereiden.

CORPvs elongatum, conuexum, craffitie pennae anferinae, rufum, fegmentis I06-1 22 compofitum, interfectionibus fegmentorum in plurimis linea duplici, transuerfa, albida notatis.

CAPVT in hac et pennata a ceteris diuerfum.

TEN TACVLA quinque articulata articulis quinque vel fex inaequalibus; tria ante oculos inferta, duo lateralia breuiora.

ocver puncta duo maiora, nigra, pone inter exteriora tentacula.

coltvm vel fegmentum capiti proximum duorum fegmentorum volumine; huic aliud iungitur fegmento pedum anguftius, fupra vtrinque corniculo erecto, cirris pedum-figura et ftructura aequali; vtrumque colli et corniculorum fegmentum abfque pedibus eft.

PEDEs componuntur fafciculo fetarum medio inter verrucam acutam et cirrum duplo vel triplo lóngiorem; bafi huius erigitur in fegmentis 5-26 rachis minima radiis tribus conftans; reliqua hoc ornamento carent. terminatur.

CAv'A filamentis duobus breuibus craffufculis 
CAPVT antice inftruitur lobis binis; fubtus inter lobos et collum rima media transuerfa, in cuius medio foramen oris e fubiacente forcipe nigricante.

In Madreporae pertufae lacunis vulgaris et in argillofo fundo.

Fig. 4: Nereidem pinnatam naturali magnitudine,

Fig. 5. vero caput fuperne fpectatum cum collo, oculis, tentaculis et labio bilobo,

Fig. 6. idem inferne areamque oris,

Fig.7 bina corporis fegmenta dimidiata, branchias pinnatas et cirros pediformes aucta magnitudine monftrat. 
Tab. XXX.

\section{FASCIOLA SCORPII.}

FASCIOLA elliptica, altera extremitate papilla minima perforata, collo nullo. Zool. d. prodr. 2709.

Dan. Vlk-ikten.

corpvs minimum, oblongum, teres, fufcum, vtraque extremitate obtufun.

porvs lateralis minimus fub altera extremitate et in eodem loco colli papilla minima poro terminali inftructa.

In cот т I Scorpii et beENnIr viuipari intertinis vna cum Fafciola br.e n nur.

Poft Clariff. zoega vtramque et ego in muco inteftinali C. Scorpii reperi; Fafciola Scorpii granulum album pellucens fub lente vitrea refert, Blennii vero aliquantum maius eft; illam fub microfcopio oculis plenam vidi.

Fig. I. Fafciolam Scorpii naturali et aueta magnitudine exhibet.

\section{FASCIOLA LVCIO. PERCAE.}

FASCIOLA ouato - oblonga, fubuentrico?, collo breui, pori terminalis margine dilatato laeui. Zool. d. pr. 27 Io.

Dan. Sandart-ikten.

corpvs ouale, ventricofum, fufcum, altera extremitate collo breui cylindrico, margineque pori terminalis integro et laeui. reetus.

porvs lateralis infra bafin colli aliquantum por-

In inteftinis Percae Lucio-percae.

Fig. 2. Fafciolam Lucio-percae naturali et aneta magnitudine fiftit. 


\section{FASCIOLA PERCAE. CERNVAE.}

FASCIOLA ouata ventricofa, collo breui, pori terminalis margine nodulofo. Zool. d. prodr. 27 II.

$$
\text { Dan. Hork -ikten. }
$$

corpvs ouale, ventricofum, fufcum, arenula paulo maius, altera extremitate auctum, collo cylindrico reEto albo, apice nodulofo marginato; porus terminalis non in centro, fed in vno nodulorum.

porvs lateralis infra bafin colli in gibbofiore parte; hinc collum non medio corporis, fed eius lateri appofitum apparet.

In Percae cernuae inteftinis.

Fig.3. Fafciolam Percae cernuae naturali et aucta ma. gnitudine oftendit.

\section{FASCIOLA AEGLEFINI.}

FASCIOLA linearis depreffiuscula, collo nullo. Zool. d-pr. 27 I 2.

Dan. Kuller-ikten.

corpvs lineare, cinereo - fufcum, depreffusculum, longitudine $\frac{x}{4}$ pollicis, extremitatibus rotundatis, altera parum acuminata perforata, a qua fpatio quartae partis longitudinis corporis diftat porus lateralis margine parum eleuato.

In inteftinis Gadi Aeglefini.

Eig. 4. naturali et aucta magnitudine Fafciolam Aeglefini monftrat. 


\section{FASCIOLA BLENNII.}

FASCIOLA linearis plana, collo e lata bafi divergente truncato.

\section{Dan. Aalequab-ikten.}

corpvs planum oblongum, album et pellucidum. col LVM bafi fere latitudine corporis fenfim anguftatum, truneatum, perforatum et diuaricatum.

porvs ventralis ad colli bafin.

In Cotti Scorpii et Blennii viuipari ventriculo et.inteftinis.

Fig.5. Fafciolam Blcnnii naturali et auko volumine confpiciendam praebet.

\section{FASCIOLA BRAMAE.}

FASCIOLA oblonga, teres, bafi attenuata, obtula, collo tereti fubincuruo. Zool. d. prodr. 2714.

Dan. Brafen-ikten.

corpvs album, oblongum, teres, inferne tenuius, fuperne fub poro laterali craffius, fupra hunc porum iterum attenuatum in collum teres, fubincuruum, apice perforatum.

porvs ventralis ad colli bafin. Infrá hunc pellucebant ounla oblonga fufca, quae animalculo in fpiritum vini immiffo elapfa funt, at non obferuari potuit, per quem porum.

In Cyprini Bramae inteftinis.

Fig. G. Fafciolam Bramae naturali, eandemgue et partem ounlis foetam ancta magnitudine oculis fiftit.

FASCIO- 


\section{FASCIOLA LVCII.}

FASCIOLA lanceolata, margine depreffo, crenato, collo elongato, tereti.

FASCIOLA lanceolata, depreffa, marginibus acutis crenatis, collo elongato cylindrico. Zool. d. prodr. 2713.

\section{Dan. Giedde-ikten.}

conpvs longitudine pollicis, depreffusculum, marginibus acutis crenulatis, extremitate inferiore lanceolata, fuperiore au\&ta, collo tereti, vltra dimidium reliquo corpore breuiore, fub angulo obtufifimo corpori affixo et terminato foramine vel poro obliquo.

Foramen alterum feu porus lateralis orbicularis, in latere exteriore anguli, quem format collum cum corpore. Hic Porus lateralis nullam omnino cum vifceribus connexionem habere videtur; fundus enim integer eft et duriusculus.

Porus terminalis in viuo corpore more extremitatum Hirudinum dilatatur et contrahitur. Libera iacet in ventriculo (nunquam obferuaui in inteftinis) Elocis Lucii, vel etiam adhaeret ope Pori lateralis. Viuum animal figura dimidio longius, gelatinofae fubftantiae eft, hinc faepius in duplam longitudinem fere fponte fe extendere valet. Minorem tamen extenfionis gradum admittit collum. 'Affufo fpiritu vini mox quafi coagulatur gelatina, et corpus figuram, quam delineatio monftrat, acquirit, quae a viui figura non nifi longitudine differt.

Haec acutiffmus Zoega, qui primus has Fafciolas de. texit, figurasque et cadauera communicauit; quasdam, non 
omnes, mihi, qui nec vnquam Fafciolam Lucii extra ventriculum obferuaui, poftea reperire contigit.

Martio 1778 in Lucio I6 lil,rarum ponderis iterum plures reperi in ventriculo, duas in inteftini initio, omnes rubras, duasque vncias longiores; poro et laterali et terminali certe affixàe erant. Collum teres, duriufculum, pellucidum; gyrus inteftinulorum tenuium verfus porum lateralem. Abdomen lanceolatum, medio vtrinque prominens, margine deprefio cumulato, aucta magnitudine transuerfim friatum. Interanea in quibusdam maxime pellucent, in aliis obfcura funt; in tres areolas diuidi poffunt: primam occupat inteftinum craffius, fubflauefcens in magnum et contiguum ziczac ductum; fecundain tres veficae maiores albicantes, remotae, quales in Echinorynchis; feries ouulorum difpa. latorum ab vtroque latere vtriusque areolae: in tertia vtraque confpicitur inteftinulum recta extenfum, nigrum, excrementis quafi repletum, in ipfa extremitate in aperturam partam definens; medio globulos tres in ferie longitudinali in vnico exemplari vidi, reliqua nimis opaca erant.

In vitro fepofitis et fibi mutuo et Taeniis vtroque poro arcte fefe affixerunt, nec fine dilaceratione auelli poterant.

In ventriculo Efocis Lucii.

Fig. 7. Fafciolam Lucii, ope micrufcopii meliori delinęarione dignam, naturali magnitudine fiftit. 


\section{FASCIOLA BINODIS.}

FASCIOLA elongata teres, poro laterali papillari, caudata. Zool. d. prodr. 2716.

Dan. Tve-ikten.

Organo Fafciolis infolito, cauda nempe filiformi, $a b$ omnibus mihi notis differt.

corpvs teres, elongatum, aequale, curuatum.

Porus terminalis maior totum apicem occupans, lateralis tertiam corporis partem remotus minor eft, prominulus; vterque in apertura papillam praefert.

Extremitas poftica cauda filiformi dimidia corporis longitudine finitur.

In inteftinis.

Fig. S. Fafciolam binodem naturali et aucta magnitudine exhibet.

\section{FASCIOLA DISTICHA.}

FASCIOLA elongata teres, poro laterali porrecto, excauato. Zool. d. prodr. 2716.

Dan. Tap -ikten.

Haec et Fafciola Lucii inter maiores funt.

CORpvs lineare teres, rugofum, extremitate poftica parum attenuatum, antica vero quafi in duo crura fiffa; horum alterum breuius Porum lateralem praefert, alterum terminalem; vterque valde cauatus eft.

In inteftinis.

Fig. 9 . Fafciolam difficham naturali magnitudine fiftit.

$$
E_{3} \quad \text { Tab. }
$$


Tal). XXXI.

\section{HOLOTHVRIA INHAERENS.}

HOLOTHVRIA tentaculis duodenis, corpore papillofo, fexfariam lineato. Zool. d. prodr. 2 S I I.

Dan. Klaebende Strand - Spröyter.

long. $21-30$ lin. lat. $3-5$ lin.

Mollufcum elongatum, cylindricum, rubrum, pellucidum, rugofum et flaccidum, puntis papillaribus creberrimis obfitum, ac ftrigis albis fex longitudinalibus absque papillis diftincum, vtraque extremitate obtufum. Puncta feu papillulae inhaerendi proprietatem fingularem, quam in nullo alio animali obferuaui, habent; quo enim loco tangitur, lappa arctius adeoque pertinaciter digitis adhaerent, $v t$ absque reiterata vi auelli nequeant.

In antica parte latent tentacula duodecim, quae pro lubitu exferit et recondit; carnofa funt, teretia, rubra, attenuata, apieisque latere extrinfeco pinnata.

INTESTINVM fordibus nigricantibus impletum erat; adiacebant vafa tenuia varie complicata, generationi forfan inferuientia.

corpvs varie coarCtare et diftendere valet, fequentique valde affinis eft.

Fiftularia reciprocans forsirahum p. I 2 I. t. 38 . f. A. huic maxime affinis videtur.

In fundo finuum inter rupes Chriftianfondenfes.

Fig. r. Holothuriam inbaerentem contractam tentaculis conditis,

Fig. 2. eandem extenfam tentaculis protrufis naturali magnitudine,

Fig. 3. eiusdem partem anticam ampliatam,

Fig. 4. eandem in varias flexuras protenfam,

Fig. 5. inteftina naturali magnitudine,

Fig.6. tentaculum valde amplificatum a latere exteriore, Fig. 7 . idem a latere interiore oftendit. 


\section{HOLOTHVRIA PENTACTES.}

HOLOTHVRIA tentaculis denis, corpore quinquefariam verrucofo. Limn. Syft. 1091. Zool. d. prodr. 2806.

Echinus coriaceus ad os fimbriatus. Planc. conch. p.99. t.6. f. D, E, F.

Cucumer marinus. rond. pifc. 2. c.25. fig. VANDELLI diff. p. 87. t. 2. f. I 2.

Comment. Bonon. 5. p. 242. t. 2. f. I-3.

Dan. Fem - raded Strand -Spröyter. Gall. Concombu de mer.

Groenl. Innelualik.

Huius figuram in Islandia ad viuum delineatam, IINNAEOque a fagacifimo rerum naturalium indagatore KOENIF olim miliam, cum plurina cum praecedente communia habet, addere, fuisque fynonymis in fyftemate Linnaeano neglectis exornare non a re alienum credidi. Numero tentaculorum denario, verrucis geminatis luteis, quarum quamlibet animal longius, quam tentacula extendere poffe roenigivs in manuferipto narrat, fpatiisque vacuis ferie verrucofa latioribus fat $a b$ $\mathrm{H}$. inhaerente differre videtur.

In Oceano Atlantico, qua Groenlandiam, Islandiana et Portugalliam alluit, ac in mari Adriatico.

Fig. S. Holothuriam pentactem naturali magnitudine exprimit. 


\section{Tab. XXXIIf. \\ PLANARIA TREMELLARIS}

PLANARIA plana membranacea, lutea, margine finuato. Zool. d. prodr. 2;05. Verm. helm. hift. p. 72 .

Hirudo plana, corpore plano ouato, antice emarginato. Ström. Act. Nidr. 4. p.365.

Dan. Slim - Flad - ormen.

long. 9 lin. lat. 4 lin.

Membrana plana, lutefcens, margine varie finuato, fupra cinerafcens, difco fublutea: in huius medio linea pinnata; infra hanc maculae duae paruae lunatae, quas inter punctum, verfus poftica punctum aliud maius circulo cinctum; haec omnia alba.

In antica dorfi parte maculae duae collaterales, quarum margine interiori lineola apicem verfus excurrit. Pone apicem denique maculae binae, ex punctis minimis nigris compofitae, in lineam punctatam productae. Haec forte oculi. Subtus albicans, macula in medio maiore ouata, minoribusque duabus lunatis pellucentibus, lacteis.

Membrana haec plerumque mere plicatilis et im. maculata confpicitur, quo ftatu Tremellis vegetabilium prorfüs fimilis eft. frequens.

In portu Havnienfi, ac in finu Chriftianienfi haud

Fig. I. Páginam fuperiorem,

Fig. 2. inferiorem naturali magnitudine fiftit. 


\section{PLANARIA ATOMATA.}

PLANARIA plana, membranacea, alba, fuperne atomis fparfis rufis. Zool. d. prodr. 2706.

Dan. Punkt. Flad-ormen.

long. $3 \frac{x}{2}$ lin. lat. 2 lin.

CORPvs fubtus album immaculatum, fupra fparfum punctis luteo-fufcis; oculo armato puncta fparfa albida quoque percipiuntur, ac ab antico quartarn partem remota puncta nigra in duos cumulos congefta; quilibet continet decem puncta, quorum fex pofteriora aliquantum $\mathrm{ab}$ interioribus remota funt, an oculi? 10cum quidem occupant.

\section{In finu Dröbachienfi.}

Fig. 3. Planariam naturali,

Fig. 4. aucta magnitudine fiftunt. 
74

\section{PLANARIA CORNVTA.}

: PLANARIA plana, oblonga, tentacula ab vtro. que capitis latere. Zool. d. prodr. $268 \mathrm{I}$.

Dan. Horn-Flad - ormen.

Animalculum inter congenera corniculis fuis fplen. didum.

cornva feu tentacula bina remota, filiformia, in margine antico, aliquantum recuruata, linea percurrente fufca, bafi atomis nigris notata; pone cornua angulus acutus ex atomis nigris compofitus; huius crura retrorfum fpectant; anticam corporis partem inter cornua interdum producit.

conpvs album, fupra vafculis pinnatis rufis, fubtus punctulis albis, quafi ouulis, paffim infcriptum, margo varie flexilis.

In finubus littoris Chriftianfandenfis, inter rupes Lynger, et in finu Dröbachienfi; illic quatuor fpecimina, hic vnicum femel reperi.

Fig. 5. Cornutam naturali magnitudine,

Fig. 6 et 7 . vero aucta magnitudine exhibent.

Tab. 
Tab. XXXIII.

\section{LERNAEA CLAVATA.}

LERNAEA corpore cylindrico, fubfinuato, orificio triplicato infra apicem roftri.Zool. d. prodr. 2753 .

Dan. Ouger - Gielle- ormen.

Totum animal 8 lin. long. I lin. latum.

corpvs conico - oblongum, fubfinuatum, album, lineis longitudinalibus rubris, oculo armato atomis glo. bularibus pellucentibus.

cork v m tenue, flauicans, apice vncinato; infra apicem nodulus, hic ope microfcopii triplicatus confpicitur, extimumque retrahi et protrudi vidi.

CAVDA feu potius fyli bini pofticae partis corpore duplo longiores albi; intus ftriati, extus punctis fparfis nigris oculo armato cernuntur, vacui vero hyalini; hi ouaria funt.

In altero corporis latere nudus quoque oculus fanguinis rubri circulationem detegit, anteriora verfus communiter fuentis, interdum retrogredientis, affuentique obluetantis. Medio aliud inteftinum in motu periftaltico vidi.

Intra ipfum collum fila bina tenuiffima motu fanguinis fimul mouentur.

Antica parte pinnis inprimis dorfalibus, oculis, branchiis et ori Percae Noruegicae fefe affigit.

Pili tenuiffmi in capite, fquamis et radiis pinnarum Cyprini fluctuantes, quorum meminit, quosque aere expreffit KLEIN. Pifc. miff. 5 . t.xi.f. 4, animalcula e genere Lernaeae videntur et forte ipfa noftra fpecies. Speciem huius generis ARISTOTELES oeflrum marinum dixit, RONDELETIVS V.2.p.78. c.8. adiecta figura defcriplit.

In finu Dröbachienfl.

Fig. I, Prior figura Lernaeam naturali, pofterior aucta magnitudine fpectandam offert. 


\section{LERNAEA VNCINATA.}

LERNAEA corpore fubcordato, roftro fimplici curuo, ore terminali. Zool. d. prodr. 2746.

Dan. Stor-torfkens Gielle - orm.

conpvs fubdepreffum, oblongum, fubcordatum, fupra medio fulco longitudinali, fubtus lamella oblonga fouea cincta. Inter hanc et bafin roftri papilla, et in poftica parte inter ouaria papillula.

rostrvm e medio corporis curuatum apice fiffo, vbi os animalis.

ov ARIA teretia, incraffata, corporis longitudine.

In branchiis Gadorum Callariae, Morhuae et Barbati et in pinnis Aeglefini. Ström. Söndm. I. p. 167. t. I. f. 7 , 8. aliam ab hac diuerfam fiftit, eamque poftea branchiis et fauci Callariae adhaerentem reperi, Lernaeamque aduncam corpore ouato, cornu roftri retrorfum defcendente dixi.

Fig. 2. prior I.ernaeam a dorfo, pofterior a ventre fpeçatam naturali magnitudine fiftit. 


\section{LERNAEA GOBINA.}

LERNAEA corpore rhomboidali, brachiis duobus anticis totidemque pofticis nodofis, cornibus binis arietinis. Zool. d. prodr. 2747.

Dan. Sand-ulkens Gielle-orm.

conpvs depreffum, fubquadratum, antice in caput productum; ex hoc vtrinque erigitur cormu introrfum arcuatum, angulis corporis anticis extrorfum et furfum oblique porriguntur brachia duo diuaricata; poftice, vbi corpus latius eft, infra angulos dependent organa brachiis fimillima, at introrfum diuaricata et conniuentia, quae ex fitu pedes diceres, at alium vfum habere videntur; vtraque in diuarieatione nodofa funt. Inter pedes a poftica corporis parte bina filamenta fpiralia, apice acuta, (forte ouaria) in corporis longitudinem protenfa funt.

os in capite fubtus, trifidum in medio marginis poftici tuberculum fiffum, vbi anus; in quibusdam pellucet inteftinum $\mathrm{ab}$ ore ad anum deductum.

cOLOR corporis albo-coeruleus, ouariorum vero eandidus eft.

In branchiis parui pifcis, quem Groenlandi Itekiudlek nominant, ac Cottus Gobio effe videtur.

Fig. 3. Delineatio prior Gobinam pronam, pofterior fipinam naturali magnitudine profert. 


\section{LERNAEA RADIATA.}

LERNAEA corpore quadrato depreffo, brachiis vtrinque tribus, cornibus quatuor rectis. Zool. d. prodr. 2748.

Dan. Berg-lakens Gielle-orm.

CAPVT orbiculare, tuberculis minimis obfitum; corniculis binis vtrinque, inferioribus longioribus pendulis, apice vero fiffura oris, cum palpis binis introrfum curuatis. coldvм breue.

CORPVS varie depreffum et conuexum, poftice craffufculum; fupra in ipfo collo lamella rotundata, deinde alia lunata, ac in dorfo duabus gibbofis ornatum; latera tribus paribus brachiorum feu organorum proftantium inftruntur; horum antica conica funt fitu paene horizontali, media fub ventrem incuruata, poftica niaiora diuaricata. Subtus inter antica papiliae duae, et infra in collo duae minores.

OVARIA corpore longiora, incraffata; inter haec in poftica corporis parte anus eft; in hunc et per totum corpus ad finem capitis acicula immitti poterat.

Partes omnes conuexae duriufculae lacteique coloris; depreffae vero molles et grifeae funt.

In Coryphaena rupeftri Zool. d. pr. $36_{3}$, quam Groenlandi Ingmingoak vocant, at non in branchiis, fed prope easdem in finubus oris totum caput inuoluit, haud frequens.

Fig. 4. Prior Lernaeam a dorfo, pofterior a ventre oculis naturali magnitudine fiftito 


\section{LERNAEA NODOSA.}

LERNAEA corpore quadrato, tuberculato, brachiis fubtus breuifimis vtrinque duobus. Zool. $\mathrm{d}$. prodr. 2749 .

Dan. Röd-fifkens Gielle - orm.

CORPvS depreffum, fupra conuexiufculum, mar: ginibus ferratis, ferieque tuberculorum quinque longitu: dinali in dorfo, fubtus concauum tuberculo medio maiori et minori anali; dentes ferrulae anteriores fubtus tuberculati, conniuentes brachiorum anticorum loco funt, quibus animalculum fefe affigit; pofteriores vero pofticorum. In interfectione capitis et trunci papillae binae ferie transuerfa in tres ramulos excurrentes, ante has papillulae quatuor transuerfim pofitae.

INTESTINVM in ventre grifeum; $a b$ ore ad anum confpicuum.

CAPVT antice obtufum, vtrinque emarginatum, ftria media pallida quafi diuifum, apice vero palpis vti in praecedente inftruetum.

oVARIA corpore longiora incraffata.

Partes omnes conuexae duriufculae et lactei coloris funt; papillae vero ventrales et cauitates grifeae et molles funt.

In finubus oris Spari erythrini, quem Groenlandi Sulluk paugak nominant, raro reperitur.

Fig. 5. Prior delineatio Lernaeam nodosam a dorfo, po: fterior a ventre naturali magnitudine exhibet. 


\section{LERNAEA CORNVTA.}

LERNAEA corpore oblongo, brachiis quatuor rectis emarginatis, capite fubouato. Zool. d. prodr. $275^{\circ}$.

Dan. Tunge - Alynderens Gielle - orm.

CAPVT fubouatum, poftice gibbum, terminatum mucronibus duobus mollibus ad latera diuergentibus; antice fuperne planiufculum, inferne gibbum.

ROS TELLA duo introrfum vncinata fub apice capitis in planitie anteriore. os in gibbofitate anteriore labio prominulo nodulofo, obtufo, fub quo palpi duo diftantes, introrfum curuati, conuergentes.

collvm inter caput et abdomeflcoarktatum, cylindricum, longitudine capitis. в васні in collo quatuor, linearia, recta, antrorfum parallele porrecta, apice emarginato, duobus fub bafi capitis breuioribus, duobus aliquantum longioribus fupra infertionem abdominis. A ВDOMEN oblongum, cylindrico - depreffum, antice planiufculum, poftice conuexum, fuperne et inferne gibbo. fum, medio coarctatum, bafi medio excifum, lateribus vtrinque in papillam cylindricam obtufam continuatis; in ipfo bafeos medio papillula alia breuior, quae anus.

ovarta bina longitudine fere reliqui corporis punctis eminentibus adfperfa, ex abdominis incifura dependentia variant vel falcata acuminata, vel ftriata, aequa. lia, obtufa; ouulis farta brunnea funt, atque membrana cryftallina, per quam pellucent oüula fphaerica, fufcorufa, conftant; ipfum corpus, caput fimul et brachia tali membranula cincta funt, inteftinaque glomerata in fupina parte vtrinque pellucent.

Branchiis Pleuroneetis Linguatulae et Plateffae ope roftellorum capitis adhaeret.

Fig.6. Prior delineatio Lernaeam cornutam naturali, pofterior vero partem onarii aucta magnitudine offert. 


\section{LERNAEA PECTORALIS.}

LERNAEA capite orbiculato hemifphaericó, abdominis obcordati papilla terminali truncata. Zool. d. prodr. $275 \mathrm{I}$.

Dan. Kuller-Gielle - ormen.

corpys album, pellucidum, fub microfcopio punCis nigro-fufcis vndique adfperfum.

CAPVT orbiculatum, poftice conuexum, verfus collum fcrobiculis duobus excauatum, fuperne außum mucronibus duobus falcatis ciliatis diuergentibus et margini incumbentibus, antice excauatum, varie fcrobiculatum et inaequale, organisque multiplicibus inftructum. Orbiculus eleuatus acute marginatus, bafi interiori capitis incumbens, et margine inferiore ciliato extra capitis peripheriam prominens. PRовоSCIS conica truncata, media inter orbiculum iam defcriptum et capitis marginem fuperiorem. Rostelca quatuor Probofcidem cingunt; quorum duo fuperiora minora parum diftantia diuerg̀entia, apice fubulato extrorfum curuata; duo inferiora maiora diftantia, erecta, bafi craffa ouata, apice fubulato introrfum flexa. mvcronva breviffimorum bafi coalitorum par ad vtrumque Probofcidis latus, et inter Roftella inferiora pone Probofcidem. Mucro alius conicus breuis verfus marginem lateralem ad vtrumque latus in eadem linea cum Probofcide. palpi duo letacei diuergentes recti fupra orbiculum. BRACHIA duo linearia, breuia, oppofita ad apicem colli, fub orbiculi margine prominulo plerumque recondita, hinc aegre confpicua.

Aнд омF, depreffum, obcordatum, lateribus rotundatum, fulco longitudinali vtrinque excauatum, terminatum papilla cylindrica, apice truncata, fetis aliquot dependentibus inftructa. 
OVARIA bina linearia, recta, ex ahdominis bafi pendula, annulata, ex orbiculis opacis fibi inuicem fuperimpofitis conftructa, quorum interftitia pellucida funt. Haec ouariorum confructio conuenit cum ea, quae in Lernáea branchiali deprehenditur. In plerisque fpeciminibus ouaria deficiunt.

pinnis pectoralibus Pleuronectis Platefjae, Lim guatulae et Fle /l incumbens ope roftellorum vncinatorun adhaeret, figuris ope microfcopii digniffima.

Fig. 7. prior L. pectoralem a dorfo, pofterior a ventue naturali magnitudine monftrat. 
Tab. XXXIV.

\section{ASCIDIA PRVNVM.}

ASCIDIA ouata, laeuis, hyalina, facculo albo, aperturarum altera laterali. Zool. d. prodr. 2730 .

Dan. Plomme - Söe - pungeń.

Facie et magnitudine prunum album refert, in vivis ouata et teres, in mortuis compreffa eft.

TEGVMENTV́m exterius membranaceum, hyalinum pallidum, pellucidiffimum, laxum, rugofis ftriis vix confpicuis obfitum. APERTVRAE binae mammillares fubaequales; quaeuis in lobos conuexos octo centrum cauum ambientes diuifa eft.

SACCvrvs albus, ftriis fubtiliffimis candidioribus quafi reticulatus, vel fibris minutiffimis vel nullis tegumento adhaeret; in mortua enim quo libuit latere devolui potuit. Margo orificiorum lineolis feptem vel octo fubcoccineis ornatus eft. IN TÉS T IN VM Vti in congeneribus flexuofum, cinereo - fufcum.

Fibrillis limo adhaerere videtur.

In fedimento argillofo portus Chrifianienfis haud infrequens; in littore oceani glacialis circa finum Caricum copiofe adeffe $\mathrm{Cl}$. pacLas in litteris monet.

Fig. I. Afcidiam Prunum in limo iacentem,

Fig. 2. facculum tegumento deftitutum, ab altero latere vifum,

Fig. 3. eundem ab oppofito latere cum inteftino pellucente fiftit. 


\section{ASCIDIA CONCHILEGA.}

ASCIDIA comprefla, fruftulis teftarum veftita, facculo albo in coeruleum tranfeunte. Zool. d. prodr. 2727.

\section{Dan. Kokillie-Söe-pungen.}

Immortalis LINNAEVS in Mufeo AD. FRJD. animalis perquam fingularis, quod Microcofmum gelatinofum nominat, mentionem facit, in pofterioribus fcriptis autem et genus et fpeciem huius dereliquit. Nulla fabula absque omni veritatis granulo exftat, hoc detegere rárae mentis erit. Primus ftupor in improuifis naturalis, fervidusque infolita detegendi pruritus Microcofmumi, AZtaeonem et Macroco/mus genuit. Mens vero fibi conftans pro Iunone euanefcentem vidit nebulam: animal Macrocofmum cum fpectris feceffit, Actacones Linnaeani in fundo maris vbique congeruntur, et Microco/mus derelictus, magnitudine excepta, in Afcidia conchilega reperitur. Maffa dicitur cylindrica, gelatinofa, fubdiaphana, cui vndique adhaerent et quam operiunt teftae concharum paruae, fabulum et varia; haec defcriptio eoufque Afcidiae conchilegae conuenit, vt quoad externam formam nihil addendum haberem, et fi maffa digitis comprimatur, dicerem quoque nihil intus reperiri. Teftaceis vero et quifquiliis caute detractis, ac cute gelatinofa fub his latente caute cultro aperta, in confpectum fubit facculus Afcidiarum folitus cum binis fuis aperturis coeruleis, ac inteftino luteo altero ab latere pellucente.

Fig. 4. Cumulum quisquiliarum teftacearum Afcidian operientium,

Fig. 5. cutem Afcidial diftenfam, vt facculus videatur,

Fig. 6 . facculum bicollem cum pellucente intefino exhibet. 
Tab. XXXV.

\section{VORTICELLA CYATHINA.}

VORTICELLA fimplex crateriformis, pedunculo retortili.' Zool. d. prodr. pag. $28 \mathrm{I}$.

Dan. Krukke-Snurreren.

Aquam marinam aeque ac fluuiatilem animalculis infuforiis oculo nudo inconfpicuis fcatere, tabula haec trigefima quinta et praecedens nona indicant. Plurima genera exiftere, iam ex appendice Zool. prodromi conftat: hic, ne tabula genera diuerfa offerret, Trichodam et Vorticellam, tantum variis fpeciebus abundantes, in publicum produxi. E Vorticellarum genere folam polypinam ELLISIr hucusque vaftiffimus oceanus obtulit." Tres fpecies, quas hic fiftere contigit, cum Vorticellis fluuiatilibus plurima communia primo afpectu habere videntur et quidem habent, penitius vero infpicienti diuerfas fefe probant. Omnes pellucidiffimae, hyalinae, capitulo moleculis varie farto, ciliis rotatoriis ac pedicello inftructae.

CA PI T VL v M cyathinae hyalinum, globofo - ventricofum ac quafi in craterem apertum margine apicis valde protuberante, tortum, ciliis, vt videtur, geminis vtrinque inftructum. Ampliatio aperturae diuerfa eft, femper tamen patet.

PEDVNCVLV longus in fpiralem retorquetur, s.c rurfus ftrictim extenditur. Bafi fefe obiectis vti congeneres affigit, aut laxatus libere circumnatat.

In aqua marina in vafculis feruata paffim.

Fig. I. cyatbinam fextuplo fitu, liberam, aut puluifculo extremitate pedicelli adhaerentem, pedunculumque fpiralem, curuatum aut reeta exterfum valde aucta magnitudine fiftit. 


\section{VORTICELLA PVTRINA.}

VORTICELLA fimplex, ápice retractili, pedunculo rigido. Zool. d. prodr. pag. $28 \mathrm{r}$.

Dan. Raaden -Snurreren.

са ріт vevм hyalino - gelatinofum, globofum, fummo apice apertum, vel claufum in papillulam productum.

PeDvereves capitulo vix duplo longior, rigidus; in fpiralem reduci nunquam vidi.

Correptio fit in fummo capite; cilia rara aegerrime et rariffime in confpectum fubeunt.

Animalculum omnium maxime defes, apice enim capituli poft longam et taediofam obleruationem minimus motus ad vitam fuftentandam et probandam necesfarius percipitur.

Puluifculo in aquae fuperficie adhaeret, plerumque folitarie, raro bina in vno pedunculo.

In aqua marina tanti foetoris, vt minima gutta microfcopio fuppofita obferuatori feruidiffimo naufeam moveat, totam fere hyemem degebat, aqua licet triduum gelu conftricta, in regelata reuiuifcebat.

Fig. 2. Putrinam valde aucta magnitudine vario fitu oculis offert; fuperior figura natantem, prima capitula bina cum fuis pedicellis e pedunculo communi ope diuifionis enata; fecunda capitulum apice retractile in papillam vel mere fphaericum; tertia et quarta ouatum apice aperto et dilatato. 


\section{VORTICELLA PATELLINA.}

VORTICELLA fimplex patinae - formis, pedunculo retortili. Zool. d. prodr.pag. $28 \mathrm{I}$.

Dan. Fad-Snurrerein.

CAPIT VLV v cryfallinum omnium pellucidiffrmum, apertura maxime ampliatum, orbiculare, bafi vero in papillam contractum, moleculis diuerfae magnitudinis paffim transparentibus. Margo aperturae reflexus.

crlia rara vtrinque confpicua,

pedvacuevs longiffime retractilis.

Dum feftiue vagatur, margo capitis orbicularis alacriter corripitur.

In aqua marina diu feruata.

Fig. 3. fuperior natantem, reliquae quinque fitum patellinae varium oculis valde aucta magnitudine exhibent. 


\section{Tab. XXXVI.}

\section{PENNATVLA STELLIFERA.}

PENNATVLA fimplex acqualis apicem verfus polypis folitariis. Zool. d. prodr.p. 3076 .

Dan. Stierne-Söe-fiaeren.

Sтrines fimplex, carnofus, aequalis, pallidus, bafi obtufus aliquantum craffior, apicem verfus hydris quinque alternis inftruitur. Hae e bafi cylindrica centro pervio tentaculis fex lanceolatis acutis, margine internoque latere fcabris feu ferrulatis cinguntur; carnofae funt vti totum corpus.

RACHIs feu officulum album, glabrum, vbique teres, aequale, liberum apice nudo vltra Parenchyma proftante; altera vero extremitate non ad finem carnofi Parenchymatis pertingit, fed incuruatum atitenuatur, ac in tenue ligamentum reafcendens cutique annexum abit.

Limo argillofo infixa viuit, extracta mox perit.

Tentacula iungi et extendi vidi motu perquam lento.

- Excrementa mucida flauefcentia in corpore cylindrico cuiusuis hydrae reperi, hinc absque omni dubio totidem ora et anus funt.

Pennatulae per mare vagari dicuntur, at hoc ftelliferaé et mirabili faltem minus conuenit.

In limofo finus Dröbachien/is rariffime. $\mathbf{1 7 7 5}$.

Fig. I. Pennatulam hydris inferioribus expanfis, fupe: rioribus claufis,

Fig. 2. partem Parenchymatis calam, bafin officulo et ligamentum in integro fpecimine operientem,

Fig. 3. officulum cum ligamento cauitate Parenchymatis extractum moriftrat. 
Tab. XXXVII.

\section{ECHINORYNCHVS ATTENVATVS.}

ECHINORYNCHVS globiferus, corpore aequali flauo, collo filiformi.

\section{Dan. Lögte-kratferen.}

Echinorynchum laeuem Zool. d.pr.p. 260 r. quem Celeb. Zoega communicauit, credidi propter plura iisdem communia; poftquam vero et hunć in Gado ipfe inuenerim, quodammodo ab hoc diuerfum cenfui, licet vterque, fi fors rurfus obtulerit, vlteriore indagatione dignus fit, ac Echin. laeuis nouo fpecifico nomine globiferus corpore acuminato, collo rugofo dicendus.

corpvs aequale luteum, cylindricum, glabrum opacum, absque omni ruga, poftice obtufum, antice in collum filiforme productum; hoc apice dilatatur in machinam fphaeroideam, pellucidam, vertice cono aculeis breuiffimis hispido terminatam. Sphaerula conftat membranula glaberrima, in qua pellucebat duplex filamentum: an organum cono feu probofcidi retrahendae inferuiens?

In inteftino Pleuroneetis Limandae.

Fig. I. Fruftum inteitini, binosque Echinorynchos telae mucofae probofcide inhaerentes,

Fig. 2. vnicum inteltino exemptum naturali,

Fig. 3. ancta magnitudine monftrat. 


\section{ECHINORYNCHVS LVCII.}

ECHINORYNCHVS corpore pellucido laeui. Åt. Societ. Havn. vol. I 2.

Naturforfcher. XII. Stïch. Seite 178. V.Taf.

Dan. Giedde-Kratferen.

corpvs cylindraceum, fubpellucidum, poftice aliquantum anguftius, obtufum, vndique glabrum, absque rugis aut annulis, ne lentis quidem ope confpicuis. Color luteus eft, mox tamen in albidum tranfit.

PRовоscrs cylindrica truncata, vncinis pro paruitate Probofcidis magnis et validis, cryftallinis vndique obfita. Ope huius organi muco, quo obducitur inteftinum vel ipfi eius tunicae villofae adeo arcte adhaeret, vt nifi violenta manu auelli nequeat. Animalculum vero Probofcidem, vt Limaces tentacula, retrahendo vncinos muco educit.

In hoc primus diverfum Echinorynchi fexum obferuaui, dum interiora eius penitius infpicerem, fexusque meliores et diftinctas figuras loc. cit. dedi., Mares femellis femper breuiores ad duplum vsque. Sacculus, burfae, membrana lutescens, et inteftinum in vtroque eadem; in medio nempe antica corporis parte confpicitur membrana pellucida, caua, in quam Probofcis recipitur, vel ex ea protruditur, quam ideo facculum dixi; ab vtroque huius latere pendent bina organa opaca, piri elongati forma, facculo breuiora, quae bur fas nomino; has moleculis globularibus plenas et vacuas vidi, vfum vero earum ignoro. Membrana totum corpus intern obueftit, Inteftinum a Probofcide per facculum pellu. cens, in corpore paffim abfconditur, ac demum ad anum pertingit. Haec vtrique fexui communia funt, interanea vero diuería. 
In mare duae veficulae maiores, in medio corporis per longitudinem dispofitae, diftantes et aequales, ac caudam verfus duo globuli minores gelatinofi, opaci, oblique pofiti ac diftantes, canaliculo vero inuicem iuncti. Defectus horum organórum in fequiori fexu eadem generationi inferuire arguit. In extremitate alia adhuc vafa ope preffionis confpiciebantur, nimis tamen confufa erant.

FEMina dictis organis deftituta a facculo aut burfis ad anum rsque ouis aut ouariis et embryonibus rel vtrisque varie fparfis foeta eft. Corporis preffione in hac et in feminis reliquarum fpecierum faepifime vidi corpufcula duplicis generis oualia et linearia exire; haec embryones exclufos, illa vero ouaria obferuationes repetitae quodammodo perfuaferunt.

In inteftino Efocis Lucii, at non in omni Lucio.

Fig. 4. Ferminam Probofcide retraeta,

Fig. 5. Maren Probofcide exferta, vtrumque naturali et aucta magnitudine,

Fig. 6. Probofcidem vncinatam valde ampliatam fiftit. 


\section{ECHINORYNCHVS CANDIDVS.} gofo, albo.

ECHINORYNCHVS corpore opaco, fubru-

ECHINORYNCHVS probofcide cylindrica, baf annulata, apice echinata. Zool. d. prodr. p. 2600.

Dan. Kringel - Kratferen.

Echinorynchos in Zoologiae prodromo adoptatos amiciffimo zoEGAE deberi, ibidem monui; huius fequentem dedit defcriptionem : corpvs candidiffimum, teres, transuerfe fubrugofum, fenfin ab vna extremitate verfus alteram attenuatum. PRовоSсIS retractilis cylindrica, bafi annulata, apice retrorfum fubtilifime echinata, in extremitate corporis craffiore. ANvs in extremitate oppofita, obtufa. Inteftinis adhaeret more congenerum.

\section{Habitat in Percae cernuae inteftinis.}

Poftquam vero ipfe his vermibus operam in pluribus pifcibus nauaui, Probofcidem cylindricam vndique echinatam fere omnibus communem effe, annulumque bafeos ex muco adhaerente exftitife, notasque differentiales aliunde petendas effe clare vidi.-

CORpvs teres, fere aequale, in viuis fubrugofum; in fpiras contortum, album, fubgrifeum, morte vero inftante et poft mortem, vel aquae fluuiali immiffum rigefcit rectaque extenditur, coloremque candidum affumit.

PR овоscis cylindrica, minor, minoribusque vncinis, at numero pluribus, quam in praecedente. Reliqua ex diario adducere libet: 
Sub finem Mártii anni 1777 in inteftino Gadi Callariae Echinorynchum candiảum reperi. Aquae fluviatili imniffus in lineam rectam fe extendebat, ac rigidus factus radiculas recentes frietas referebat, glaber, absque ruga oculo perceptibili, altera extremitate appendicula proftante in angulum acutum inflexa; haec opo microfcopii fimplicis n.3. probófcidem apice et lateribus vncinulis retrouerfim armatam cryftallinis monftravit; aquae vero marinae immiffus fefe corrugauit, ac in arcum flexit; omnes tum probofcidem retraxerunt, parsque antica in quibusdam conico-obtufa, opaca; i aliis membrana laxa pellucida videbatur.

Medio Aprilis rurfus Gados diffecui ac Echingo rynch. candidum macula oblonga aurantia vtrinque pone apicem, probofcidem ipfam et apicem calidae aurantium inueni, craffioresque totos aurantios reperi. Alter craffior rufus probofcidem videre non permifit, fegmentis corporis magis confpicuis, vterque in corrugatione poftice acuminatus. Alter Gadus in ventriculo habuit reliquias fquillae aurantias, alter fucum rubrum, an dehinc quoque herbiuorus dici poteft?

Verfus medium OAtobrem duos Gados barbatos luftraui, at in vifceribus folis Echinorynchos cantidos circiter duodecim in fingulo reperi. In his quoque fexum diuerfum corpufculaque oualia et linearia vti in femella Lucii offendi. Mas cancidid interaneis gaudet, qualia in mare Lucii defcripfi, at infra binas veficulas ferie minorum globorum fex aliquantum remota inftruitur, femella femper minor mas eft. FEMINA maioribus et minoribus veficulis deftituta, a ventriculo ad anum vsque nihil diftincti oculo armato in nonnullis, in vniço tamen fubftantiam reticularem nigricantem per aream totam longitudinalem effufam obtulit; vtraque compreffa oumla explofit, in hac quoduis areola quafe limofa 
limofa cinctum, in illa nudum, at corpufculis linearibus ftipatum. Sacculi collaterales in quibusdam flauicant ac pellucent, hinc lineola flaua pone probofcidem et inter: dum apice eiusdem in corpore candidiffmo oculo pulchrum animal exhibet.

Sub initium Novembris inteftina Gadi Merlangi in quatuor fpeciminibus percontabar, inteftinumque reEtum totum Ech. candidi longitudine maximam partem 2 vnciarum, ac numero $40-50$ in quouis horridum reperi.

Primo Decembris in inteftino Cyprini Idbari Echinorynchum album longiorem et alium aurantium breviorem ac collum verfus craffiorem reperi; ex analogia pofteriorum marem credere fas erat, at vterque feminini fexus erat, omnesque cohabitantes, quorum duodecim prefforio fexum extorfi; neque vllius marem in. venire potui, licet omnes, vnico excepto, ex intertino oblatos examini fubiecerim; fimiliter in Perca cernua die 24 Ianuarii 1778 inquifitae omnes feminae erant; $e$ contra in Gado Merlango, die 14 Novembris perquifito, omnes Echinorynchi laeues mares erant.

Sub exitum anni Gadum Callariam luftraui, to. tumque inteftinum a pyloro ad diftantiam vnciae $a b$ ano Echinorynchis vltra ducentis obfitum reperi. Plerique candidi erant, mares breuiores, feminae longiores; aderat paffm alia breuior femina, rugofa vtraque in extremitate et toto corpore aequali craffitie, colore flavefcente, ac fub ipfa preffione opaca; Probofcis huius, vti candidi, aculeis minimis plurimis confertis obfita, vtramque microfcopio et prefforio fubieci, in flauefcente tamen nec veficulas et globulos, nec ouula aut ouaria videre potui. Singulare et rarum phaenomenon.

Calyptra, 
Calyptra, qua extremitas poftica in nonnullis Echinorynchis tegitur, quam animalculum deponit, quaeque ope aciculae auferri poteft, conftat membrana mucofa.

In inteftino Gadi barbati, Meriangi et Callariae, Percae cernuae, Cyprini Idbari et Lophii pifcatorii frequens obuius. Perilluftris comes а вогске Stargardtienfis, eximius naturae fcrutator, in Strige reperit.

Inteftinum G. Callarias craffus, quam in aliis Gadis minoribus.

Inter Echinorynchos paffim aderant 8-10 Afcarides filiformes, pallidae, fufcae.

Fig. 7. Echinorynchum candidum libere in muco inteftinali iacentem,

Fig. 8. eundem rigidum tunicae viliofae inhaerentem, vtrumque naturali magnitudine,

Fig. 9. vero et Fig. ro. partem corporis anticam et probofcidem vneinulofam ampliatam fpeetandam praebent. 


\section{ECHINORYNCHVS LINEOLATVS.}

ECHINORYNCCHVS corpore lineolis transuerfis fufcis, medio interruptis.

ECHINORYNCHVS probofcide cylindrica echinata, inflexa, corpore filiformi rugofo. Zool. d. prodr. 2599. Taenia haeruca. Pall. Zooph. 415.

Dan. Streg - Kratferen.

Hunc fequentibus verbis defcribit Celeb. zorGA: coRpvs filiforme, vtrinque obtufum, rugis transuerfalibus dimidiatis. Рв овозсіs retrątilis, cylindrica, fubtiliffime et denfiffime retrorfum echinata, in extremitate parum craffore fubincurua. Ávv́s terminalis in extremitate oppofita. Exferta probofcide oris annulus distentus et glaber eft; retracta vero probofcide, os videtur bilabiatum, labio fuperiore craffo prominulo, verticaliter triplicato, inferiore arcuato laeui.

Habitat in Gadi Lufci, Merlangi, Callariae et Cotti Scorpii inteftinis, probofcidis ope arcte adhaerens.

Quinto Aprilis anno 1777 diffecui tres Gados $A e$ glefinos:

IN TES r IN vm pellucidiffimum, fubtili luto plerumque repletum; paffim pellucebant vermiculi fpirales, albi, rufi et nigricantes diuerfae longitudinis, rugofi, aquae vero fluuiatili immiffi rugofitatem et fpiralem contorfionem amittebant, recti breui et rigidi extenfi, glabri facti funt, ac protenfa probofcide echinata genus et fpeciem prodebant, (Echinoryn. nempe candidi). Quidam longiores et craffiores lineolis tiansuerfis nigris notati, ac linea longitudinali ab vtroque latere pallida, an fpecie diuerfi. (Echinorynch. lineolat.) In quibusdam minorum lumini obuerfis pellucebat feries globulorum albidorum verfus poftica (hi mares). Ab Echinor. Gadi Callarias differebant abfentia membranae feu vaginae anticae 
anticae pellucidae. Craffores nigricantes infra apicem, probofcide non exferta, montrabant binas papillulas, labiumque fuperius imminens. Probofcis vncinulis fedecim ad ninimum ferierum longitudinalium infruebatur, in iunioribus diftinctioribus, in maioribus nigricantibus ex parte obliteratis. Situs probofcidis ad angulum obtufum. Parieti inteftinorum non adhaerebant vti congeneres, fed luto iniacebant, forte relaxauerant fe fenfu pifcis pridem mortui. Maculam oblongam ad latus oris fub apicem caudae in his nullam vidi.

\section{Octauo Aprilis diffecui duos Gados Molvas.}

Echinorynchi, vti in Gado Aeglefino, albi, minores absque lineolis, et maiores lineolis transuerfis nigris, in ipfo luto inteftinorum. Breui in aqua fuuiatili recta et rigidi extendebantur, lineolis tamen perfiftentibus; ani veftigium nullum detegere potui; poftica extremitas rotundata, teres, glaberrima et laeuis; lineolatae vitra duas vncias in rigore.

Die decimo fexto OEtobris vifcera trium G. Merlangorum percontatus fum; in vno nullum, in reliquorum fingulo 5 Echinor. lineolatos reperi. Femina mare congeneribusque robuftior et longior, vltra duas vncias, opaca, ne oculo armato quidem pellucet, corpufculis tamen oualibus et linearibus a ventriculo ad anum reple. ta; preffa enim innumerum praefertim linearium numerum emifit; pauca oualia; cumque linearium pauca reliquis minora erant, oualiaque in hoc fpecimine rara effent, ea ouaria potius, quam oua effe, linearia vero veros embryones; hoc quoque confirmare videntur lineolae curuae in ouariis pellucentes, ac in ouariis etiaporatione ruptis refiduae.

Mas aliquantum pellucidior interanea, qualia in Echin. candido, a quo vix vllam differentiam reperire potui, confpici praebet. 
Saepe apex caudae in Echinorynchis vaginula opa. ca inftruitur, quae preffioné exuitur.

IEEUWENHOER primus fingulare huius generis animalculum detexit, anticamque corporis partem cum protracta probofcide figura adornauit; dein clariffmus Palras in diff. de inteftin. viuent. nomine Haerucae, poftea in Zoophyt. elench. Taeniae haerucae, et demum in XIX.vol. nov. Comment. Acad. Petrop. eius meminit, figuramque t. 9. f.'2, ex inteftinis Ranae temporariae adiecit; an vero fit a meis fpeciebus diuerfa, nec ex defcriptione, nec ex figura fufficienter patet. Alium Cel. KOELREUTER fub nonine acanthocepbali l.c. v. XV. t. 26. communicauit. Hic in Cyprino Rutilo inuentus ab illo, quem ego in eodem pifce reperi, valde diuerfus eft, a ceteris collo probofcide anguftiore diftinguitur. Probofcis cylindrica, apice truncata, vncinulorum feriebusad minimum octodecim, vncinulisque decem in quauis, hinc circa ducentis tunicae villofae adhaeret.

Huius et praecedentis fpeciei quidam in aqua flu. viatili vltra triginta horas vitam produxerunt.

In plerisque Gadi fpeciebus Echin. canditi et lineo: lati reperiuntur, hinc nomen Gadi triuiale in lineolatum mutaui.

Fig. I I. Echinorynchum lineolatum corrugatum,

Fig. I 2. eundem extenfum naturali,

Fig. I3. anticam eius partem in extenfione cum pro. bofcide exferta,

Fig. I 4. eandem partem corrugatam cum probolcidè retracta et condita aucta magnitudine fiftit.

Tab. 
Tab. XXXVIII.

\section{CVCVLLANVS MARINVS.} tufus.

CVCVLLANVS cinereo lutcus, antice ob.

Dan. Hængel-Hætte-ormen. Spids-Hætteormen.

Species huius generis prima facie Afcarices refe. runt, penitius vero infpectae nouum genus, guod ex fingulari capitis altera pagina impreffi feu foueolati ftructura cucullum mentiente Cucullanum dixi.

Vermis fingulariffimus cirrisque flexuofis longis fplendidiffimis Hydram fluuiatilem primo afpectu adeo reuocat, vt, nifi inteftinalis effet, eandem crederes; microfcopio vero vifus dubium excitat, quidnam fint filamenta feu cirri corpore duplo longiores paffim maculis nigris notati. Tubuli funt membrana fubtili pellucida et reticulari conftantes, partim vacui, partim materia nigricante expleti, quae paffim in corpufcula oualia fparfa eft. Haec ouula videntur, adeoque tubuli fex totidem ouaria, extra corpus nouo phaenomeno cirrorum inftar fluitantia; vermem enim varie ea mouere vidi, parsque corporis, quam quisque anticam diceret, poftica eft.

CORPvS pellucidum oculo armato friatum, antice in tuberculum obtufum productum; hoc altero latere quafi ftigmate impreffum foueam obfcuram exhibet, vbi os vermis adeffe videtur. IN TESTINVM rufum, in nonnullis femel et bis interruptum eft; in cirrato exemplari vltra medium, in integro in medio corporis nodus protuberans rimula perforatus, qui vuluam denotat; intra hanc et poftica in cirrato corpufcula fparfa, iis fimilia, quae in tubulis videntur. 
Bina tantum cirrati vermis fpecimina et quidem diuerfo tempore, in altero cirri quidam abrupti erant. Aliud fequioris fexus faepius reperi duplo fere longius, cauda integra, apice acuminato, in reliquis cirrato fimile; hoc idem effe cum cirrato, pofticamque matris partem inftante partu in fex ouaria tubulofa dirimi, cute externa, nefcio quo modo, euanefcente, autumarem, nifi quoque feminam integram oula e rimula vuluae in guttula aquae microfcopio fubiecta enixam effe vidiffern.

Mas a femina integra fola nota fexus diftingui videtur; eo enim loco, quo cauda attenuari incipit, ac vbi anus effe folet, exferitur aculeus fetaceus nigricans, bicufpidatus, hic tamen plerumque intra corpus latet, tuberculum vero vuluae in feminis femper confpicitur.

Marem cirratae feminae diu quaefiui, at cum eum, feminamque integram cum huius mare vna cohabitaro viderim, cirratam et integram eandem effe fufpicio haud leuis eft.

Muco inteftini interảum adeo obducuntur, vt hirfuti toti videantur.

Nouo generi Echinorynchum lacuftrem, cuius no. men in Zoologiae prodromo 2598 dedit Cl. zoEGA, iungere oportet. Accuratius dicitur Cucullanus lacuftris, rufus antice trinncatus. Viuis et viuaciffimis foetibus fcatentem in Perca flumictili reperi fanguineo inteftino fplendidifinum vermem, cuius quoque mentionem fa-

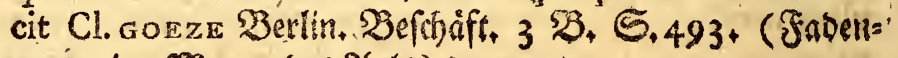
rourm im Magen bes 2 (als).

In inteftinis Gadi rarus. 
Fig. 1. Cucullanum cirratuni naturali,

Fig. 2. eundem aucta magnitudine exhibet:

Fig. 3. Partem corporis cum vulua et ouulis,

Fig. 4. partem cirri cum ouulis dispalatis,

Fig. 5 et 6 . frufta membranae cirri reticulatae;

Fig. 7. ounla bina confpicienda praebet, omnia haec valde ampliata.

Fig. 8. Cucullanum integrum naturali magnitudine fiftit

Fig. 9. Feminam cum vulua in medio corporis,

Fig. I O. marem cum fpiculo genitali exferto,

Fig. I I. caudam maris muco obduktam aueta magnirudine offert. 


\section{E R R T T .}

Dag. 9. lin. 21 . quaelibet, leg. quolibet. p. 15.lin.3. inuoluti viui, leg. inuoluta, viua., p.21. lin. x. Horoth. leg.Holoth. p. 25. lin. 14. baec leg. boc. p. 30. lin.25. laewus leg. laeuis. p. 31 .

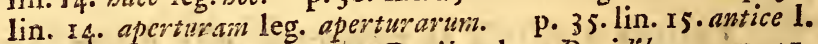
antico. p. 36. lin. 6 et 8 . Doribus leg. Doridibus. p. $4 \mathrm{r}$. lin. 26. prima leg. pima. p. 64. lin. 17. maius oeulis leg. maior onulis. p. 65. lin. 14. Fig. 1. leg. Fig. 3. p.68. lin. 6. longiores leg longos. p. 68. lin. 1o. cumulato leg. crenulato. p. 68. lin.23. Jepofitis leg. Jepofitae. p. 69. vlt. Fig.3. leg. Fig. 9. p.71. lin. x2. Concombu leg. Concombre. 


$$
+2
$$

. 



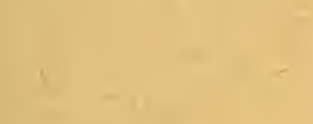




